\title{
Sequelae of treatment of labio-palatal clefts, experience in an island community
}

\author{
Jean-François BARON
}

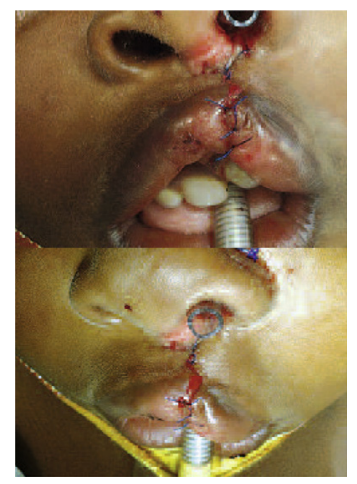

\begin{abstract}
The author presents the sequelae of labio-maxillo-palatal clefts in the specific framework of one surgeon's professional experience in an overseas community; in terms of their surgical anatomy, showing the palatal, maxillary, and labio-nasal sequelae in order, emphasizing the intimate relationship of the lesions, which are most intricate in cases of complete labio-palatal clefts, and also the necessity of the treatment team's taking a global approach in the techniques of facial surgery so the results will be well adapted to the social needs of patients.
\end{abstract}

\section{KEY WORDS}

Palatal sequelae

Maxilla

Labio-nasal

\section{$1-$ INTRODUCTION}

Labio-palatal cleft

I have limited my commentary to presentation of the sequelae of labio-maxillopalatal clefts that, because of their relatively frequent occurrence and their diversity, occupied a special place amidst the pathological facial deformities I encountered over the course of twenty years of practice on the islands of Maurice, Mayotte, and La Reunion, so deeply isolated in the Indian Ocean that the system of referral to specialists for treatment is far more limited than it is in European centers. Some of the therapeutic difficulties I encountered were caused as much by the variable socio- economic conditions as they were by the severity of the anatamo-clinical defects. Just as the original malformation may affect all the facial elements lying between the upper lip and the uvula, the iatrogenic defects resulting from faulty or unsuccessful primary interventions can occur anywhere in the region of the clefts and must be repaired as well as possible by the surgeons of "second intention," who should always bear in mind the truth of the old adage, "criticism is easy, art is difficult" as they rehabilitate not only any traces of the original malformation but also try to mask the inadequacies of 
the first surgery, the most severe of which are not, oddly enough, the most difficult to correct. These surgeons must reframe a coherent sequence of therapy, based on an exhaustive knowledge of facial surgery, which is the critical element in their treatment of malformations of patients from birth into adulthood.

\section{2 - FOUNDATIONS OF THERAPY}

Ideally, a therapy team for lifetime management of labio-palatal clefts consisting of a plastic surgeon, a pediatrician, an otolaryngologist, a speech therapist, and an orthodontist can be organized even before the patient's birth thanks to the discovery of the defect by ultrasound examination sometime during the second trimester of pregnancy. One of this group's goals will be to reduce as much as possible the sequelae that result from inadequate execution of initial surgical procedures that can be as difficult to correct as the original defects themselves. Even though treatment teams operate in accordance with calendars that vary from one hospital center to another, they all share the same goal of coordinating and timing the efforts of all the specialists in an attempt to obtain the best compromise of the sometimes conflicting interventions designed to improve the phonation, occlusal, and esthetic status of patients.

The quarrels between different schools of cleft treatment being of interest only to the passionate gurulike leaders of the contentious groups, all new professionals on first entering the field of cleft palate therapy have to define for themselves the program best adapted to the moment they come into contact with their mal- formed patients being careful not to use irreversible procedures or ones that cannot be integrated into a logical and well-tested course of action. As for me, I began working in this field under the direction of $A$. R. Chancholles $^{2}$, a surgeon who emphasized the importance of helping cleft palate children in phonation by providing them with palatal, obturator plates soon after birth. This procedure required a certain level of technical skill and follow-up attention that was never available in the isolated communities where I practiced. So I began to utilize other protocols that I thought better served the needs of my widely dispersed group of patients.

I associated myself with the work of J.-C. Talmant, a devoted surgeon in this field and I now take advantage of this article to pay heartfelt homage to him. For more than 15 years I have adopted his strategy in my overseas hospital practice, now especially concentrating on correcting the sequelae of these malformations that different specialists in different locations in teams that might not necessarily have the same supplies and equipment will have to deal with. These procedures include plastic surgery for the soft tissues of the nose and lips, oral surgery for osseous and mucosal defects, and orthognathic surgery for protrusions or retrusions. 
Just as in the original surgical procedures, all corrections of sequelae of clefts must focus on function as well as form, but must also overcome the constraints caused by primary interventions often overlapping in anatomic space and time. A hidden initial error can abruptly appear to counter-

\section{3 - PALATAL SEQUELAE}

Sequelae in this area probably cause the worst problems because they interfere with phonation and thereby exert an adverse effect on the social life and the academic endeavors of patients. Accordingly surgeons should correct them before patients enter school. But full success can only be achieved for patients who, from birth, have benefited from favorable medical care in which a major role is played by speech therapy, a service that is rarely available in the remote island regions where I practiced.

Palatal defects, invisible to others, were neglected by the patients I encountered, who were more concerned by the negative effects on their appearance caused by associated labio-nasal malformations. These two intricately entangled forms impede language skills and, whether patients admit it or not, their interpersonal relations suffer at every stage of their lives.

\section{3-1 - Dealing with gaps in nasal and oral cavity integrity}

\section{- Prevention}

J. -C. Talmant ${ }^{10}$ expressed, far better than I can, the basic principles act the most recent correction, which most likely will not be the last.

In the interest of clarity we shall illustrate these sequelae through their surgical topography, portraying cases that reflect most typically the therapeutic ambiance of their management.

of cleft palate therapy: closure of palatal cleft by sliding procedure only at 18 months taking advantage of the spontaneous shrinking of the osseous defect that follows simultaneous growth of the soft palate and the lip at 6 months. (In some cases I have postponed palatal surgery for a year while waiting for this favorable anatomic development to be completed.)

\section{- Absence of treatment}

Apart from major functional detriment, not instituting active treatment at the sequelae stage does not constitute a real obstacle to proper technique, furnishing the treatment team an opportunity to update procedures deemed to be iatrogenic ${ }^{7}$ by leaving osseous zones denuded as a source of pushback, retraction along the alveolar arches that proves to be highly useful with large clefts where it allows only required medialisation of the flaps (Figs. 1 and 2).

- Treatment of palatal gaps losseous disunion, soft or hard palate fistulas)

The functional effects of gaps not being necessarily correlated to the size of the defect, their closure is paradoxically highly delicate because it requires adjustment of sclerotic and inflamed tissue whose dissection 


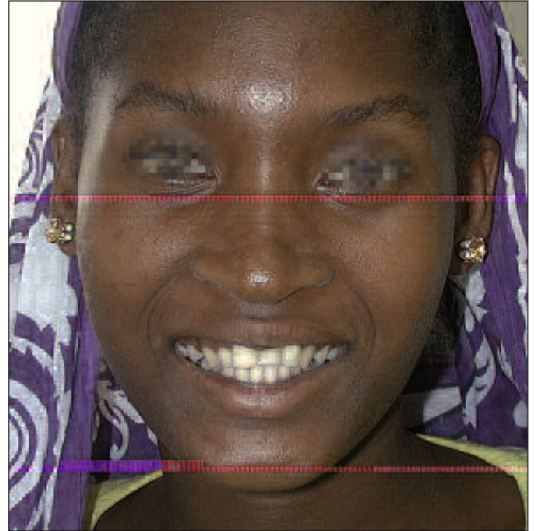

a

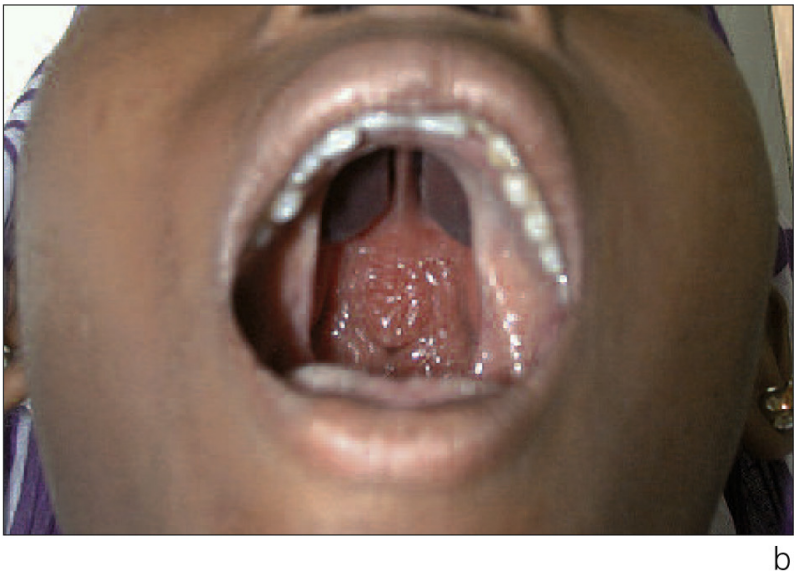

Figures $1 a$ and $1 b$

Palate not yet operated upon.

A resident of the overseas department Mayotte, this patient clearly showed that the absence of treatment of the palatal mucosa coincided with the harmonious growth of the maxilla. But her difficulty in speaking clearly was severe. Her school teacher commented, "She is a good student but she never speaks in class."
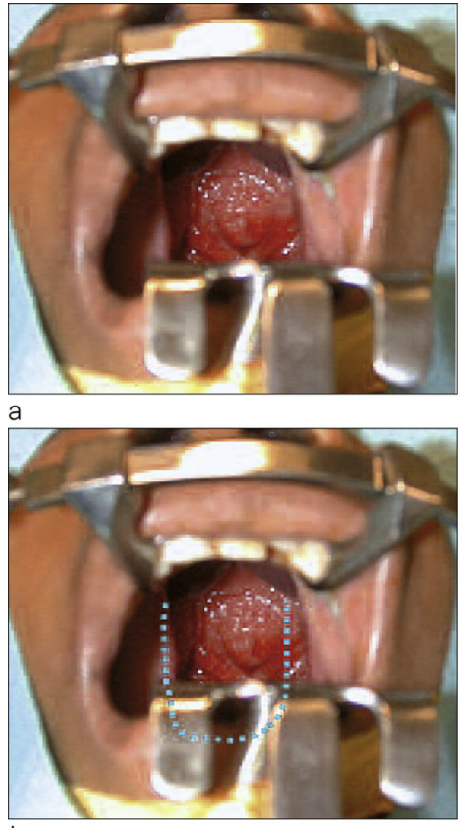

$\mathrm{b}$
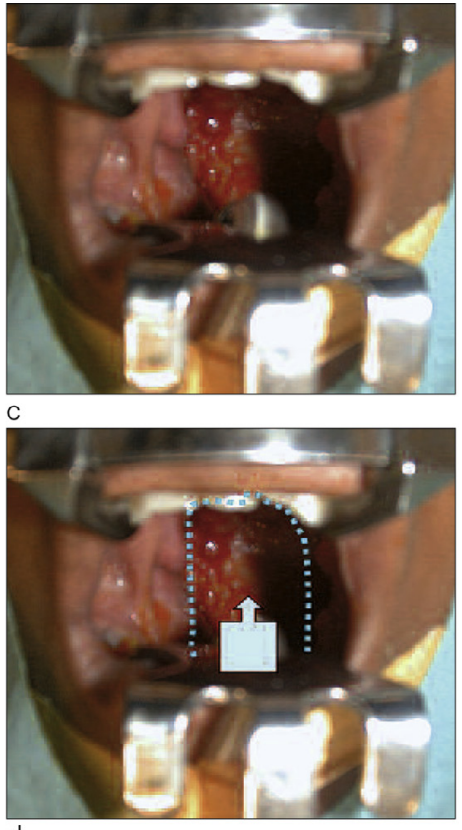

d
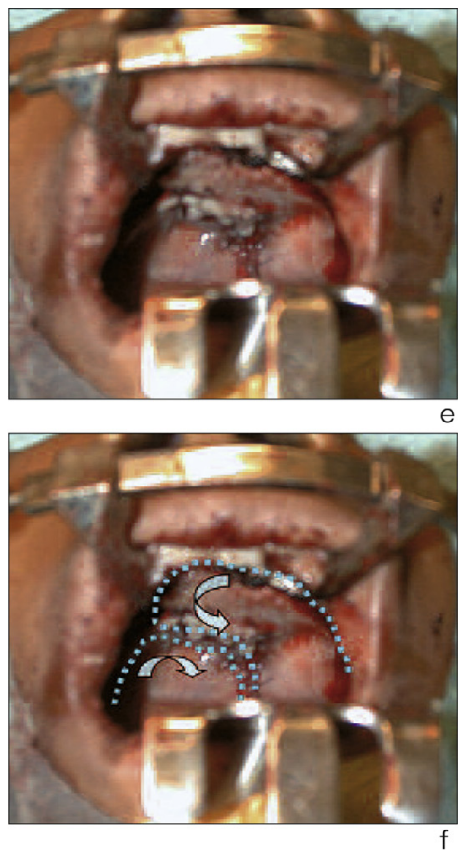

Figures $2 a$ to $2 f$

Detailed views of the procedure.

Pharyngeal upper Sanvenero Rosselli flap (a and b) started in anterior palatal zone for nasal reconstruction (c and d) with simultaneous improvement of velar-pharyngeal competence. Two asymmetric fibro-mucosal flaps (e and f) have been made. The larger on the left, by its counter-clockwise rotation provides for the greatest possible covering of the soft palate. The smaller right flap provides the push back. 
must be undertaken in totality in order to obtain good palatal and nasal seals: surgeons routinely underestimate the difficulty. It is sometimes impossible to obtain a nasal seal. Obtaining the viability of the palatal plane, which is imperative, depends upon the choice of the fibro-mucosal mobilizations, sometimes accomplished in two stages (Figs. 3 and 5). I have not yet had to utilize tongue or distance flaps for this indication.

\section{3 - 2 - Velo-pharyngeal incompetence}

Apart from the presence of a submucosal or an untreated cleft, it is the speech therapist who plays the largest role in how to deal with labio-glossodental problems frequently associated with labio-palatal clefts. Rhinolalia, excessive nasal quality of the voice, is pathognomic lack of rhino-pharyngeal closure, but it is often masked by a voice emerging from the facial grimace of a patient reluctant to participate in speech therapy. This and other para-clinical criteria ${ }^{2}$ have been used to bolster indications for a surgical cure. I have not had this type of experience but have made decisions in conjunction with speech pathologists, being influenced, of course, by the severity of the deficit for the patient.

From a surgical standpoint, except for the rare instances of short and supple soft palates that can be

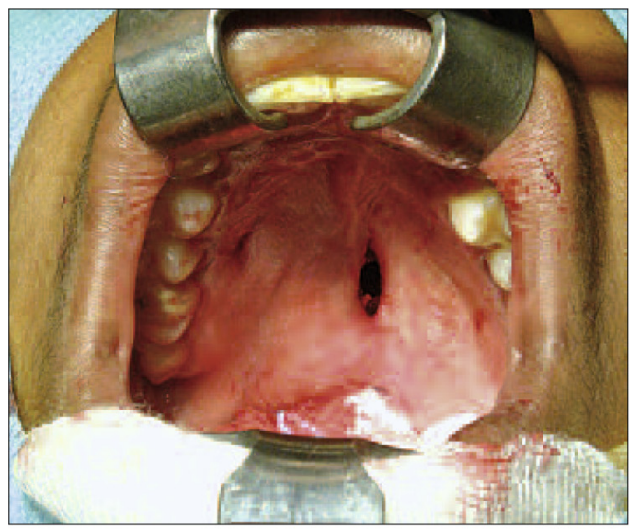

a

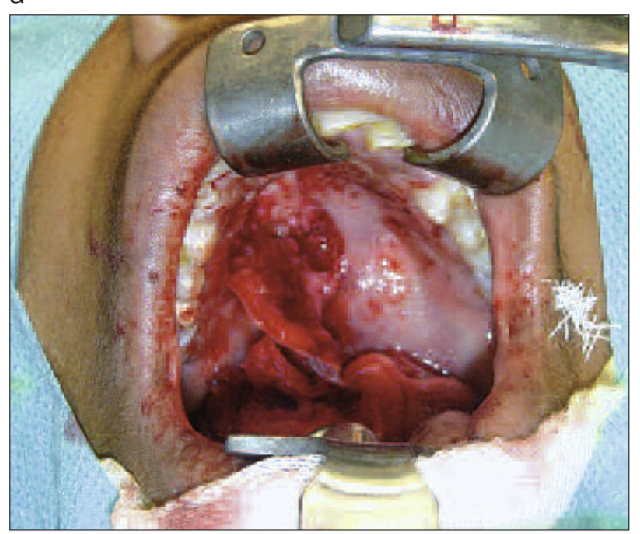

C
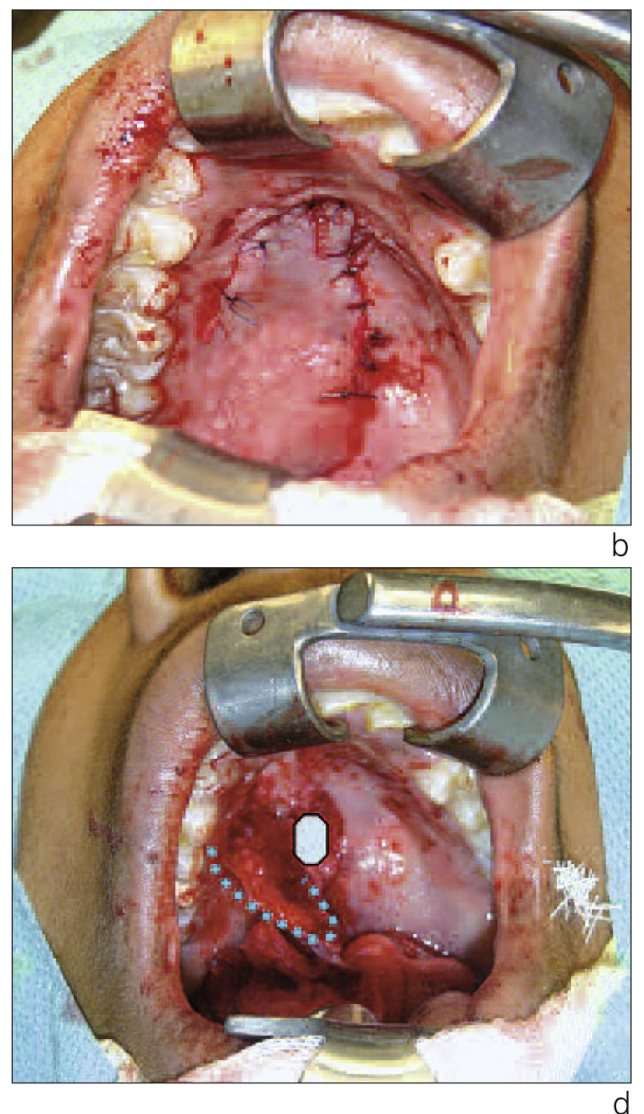

Figures $3 a$ to $3 d$

Palatal breech.

Complete reflection of a palatal flap distally (a and b) has given the surgeon the access needed for two-level repair and mobilization of the fibromucosa. The elements dissected are outlined in $c$ and $d$. The nasal breech is closed. 


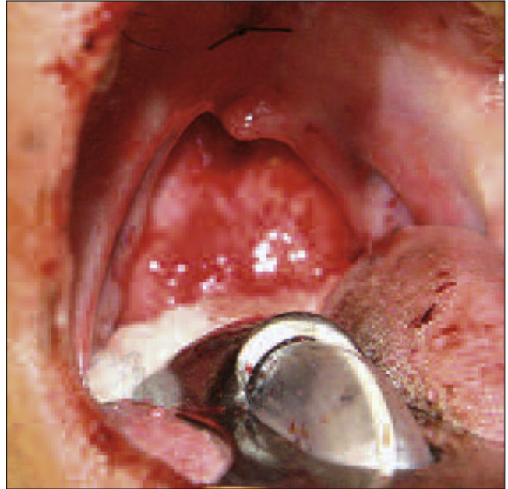

a

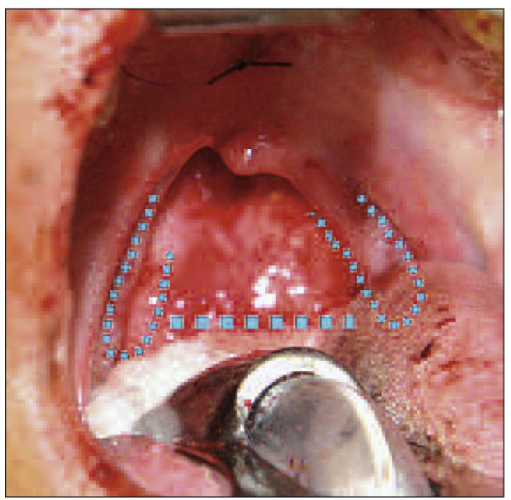

b

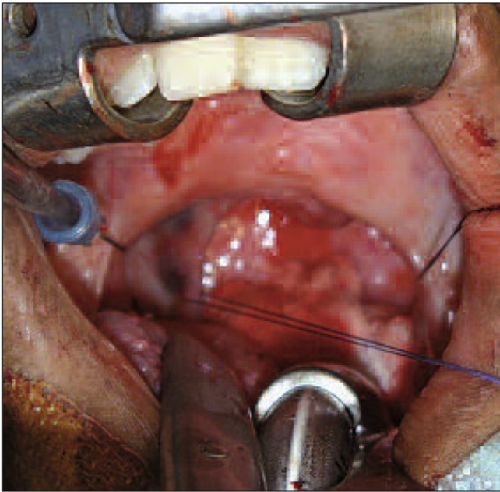

C

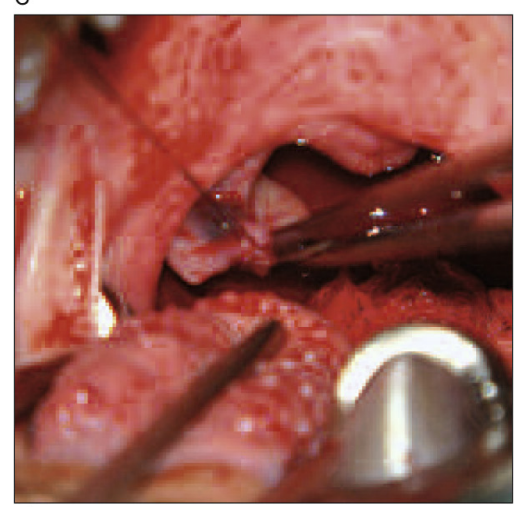

d

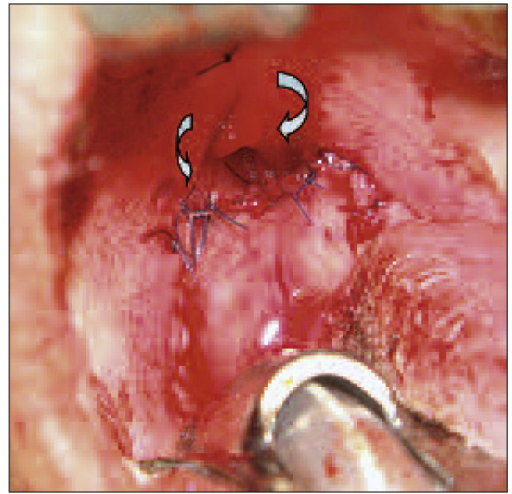

e

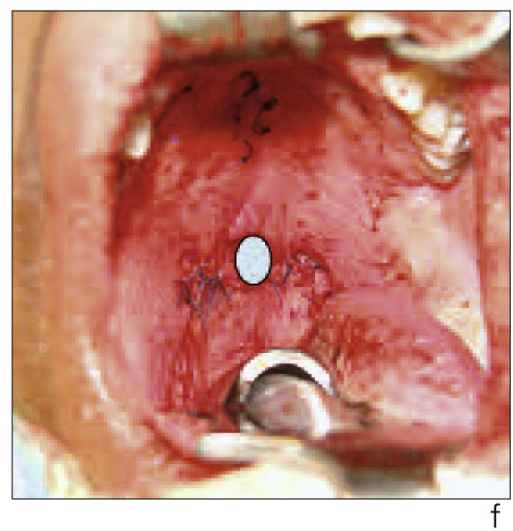

Figures $4 a$ to $4 f$

Orticochea pharyngoplasty.

This technique was used in the case just described where the patient had a short soft palate and velo-pharyngeal incompetence (a). the blue dots trace the planned flaps to be laid back from the posterior pillars of the soft palate (b) exposure (c) and raising (d) of the right flap. View at the close of the intervention centered on the pharyngoplasty ring (e) and view of the ensemble with the palatal suture, above, and the caliber of the ring highlighted (f).

repositioned without grafts, short fibrosis soft palates or clefts at a distance from the posterior wall have traditionally been treated with a pharyngoplasty using the Sanvenero Rosselli or Rosenthal flaps (Fig. 2). But today most surgeons use Orticochea's pharyngoplasty ${ }^{5}$, an astute procedure taught to me by A.R. Chancholles, a fervent advocate of the technique that creates in this crossroads area of a short loop of velo-pharyngeal-facial unity ${ }^{1}$ a dynamic sphincter whose advantages in phonation are incomparable, even in adults whose diction habits are sometimes considered to be irreversible. So I have no hesitation in using a secondary palatal flap in the right circumstances (Figs. 4 and 5). 


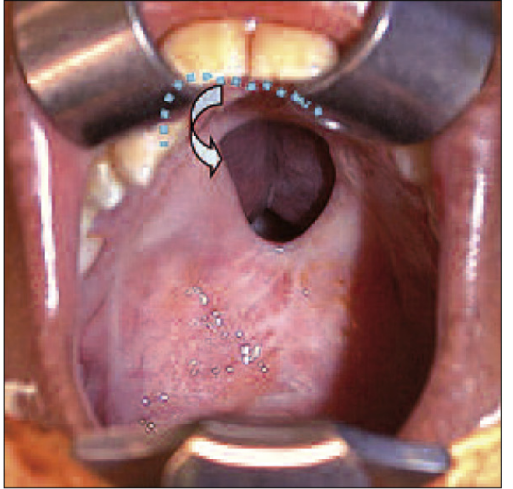

a

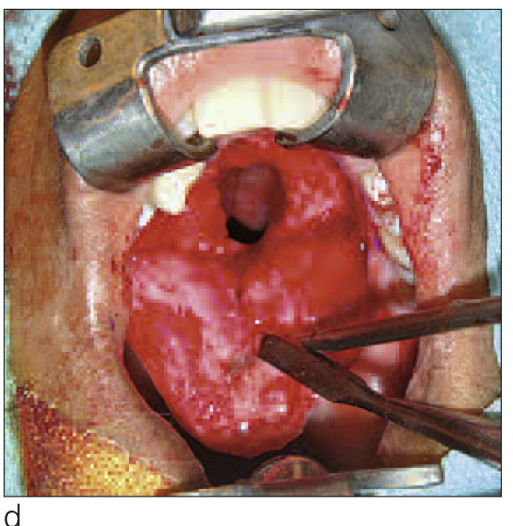

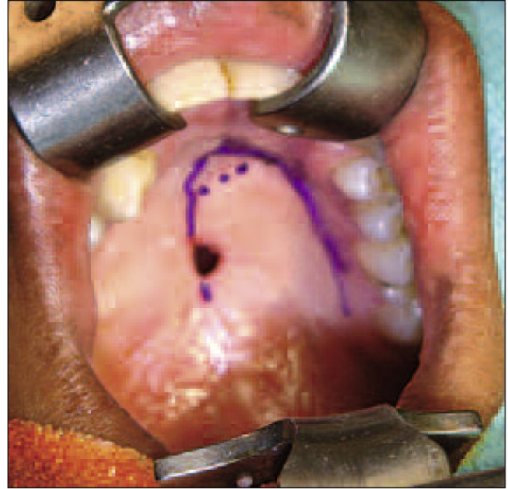

b

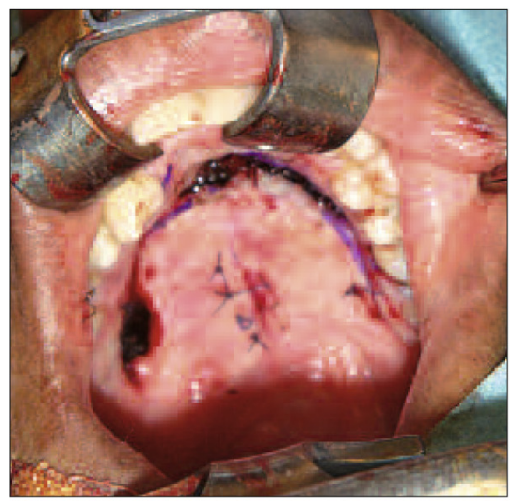

e

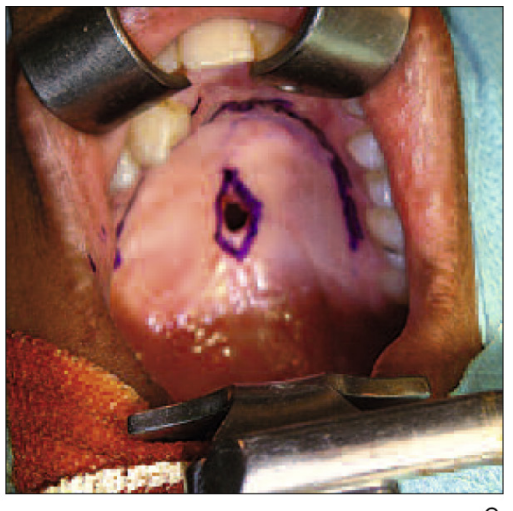

C

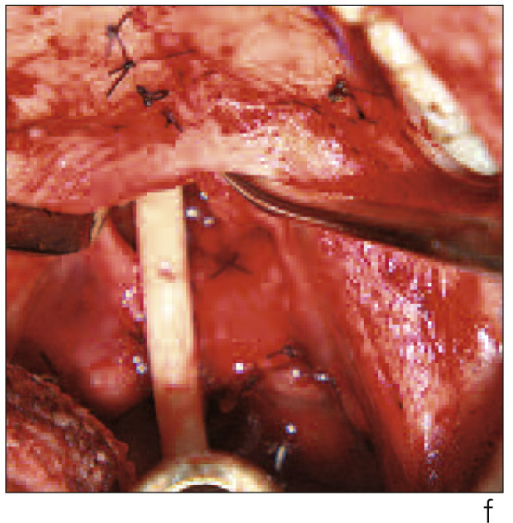

Figures $5 a$ to $5 f$

Loss of anterior substance in the healing palate.

The surgeon was unable to cover the entire gap (a) with an initial rotation flap but did make the lesion more accessible for a follow-up repair (b). Given the repositioning caused by scarring in the anterior region, the surgeon laid a bipedicle flap (c) instead of the usual single pedicle flap. View of the non-reparable nasal breech (d). The final suture of the palatal fibro-mucosa (e), accomplished at the same time as an Orticochea pharyngoplasty. A gastric tube is shown in the ring (f).

\section{4 - MAXILLARY SEQUELAE}

Maxillary sequelae, which are better understood by our orthodontic colleagues who have to deal with them directly, result from serious labioalveolar clefts and labio-palatal clefts that are worsened both by the growth deficit inherent in the malformation and lack of early treatment or poorly executed early treatment. The dental occlusion and the esthetic needs of the maxilla constitute the base for their correction. As J. Casteigt has put it, "You can't build a house without first having poured its foundation.

During its development of from infancy until the end of the growth period, the sequelae of maxillary clefts take two forms, both successive and associated, in the relatively young adults I have seen in my island practice. 


\section{4 - 1 - Solutions for lack of continuity of the maxillary arch}

\section{- Prevention}

Early treatment of the alveolar cleft with a bone graft secures an environment that encourages proper modeling of the arch and the propitious eruption of teeth. Surgeons undertake this procedure well before eruption of canines with most treatment teams expanding the maxillary arch orthopedically and then placing bone grafts ${ }^{3}$ for 4 to 6 year-old patients. This procedure makes room for eruption of lateral incisors, allows for replace- ment of gingival and mucosal tissue, and restores alveolar continuity, thus stabilizing the bone fragments around the clefts and preparing for later orthodontic intervention. When proper medical and orthodontic cares are not available, surgeons can perform these services in the course of primary treatment (Fig. 6 and 7) with the goal of improving the dental prognosis.

\section{- Treatment}

Even if small, the entire buccal fistula must be closed because it is the outward manifestation of what might be a more serious retro-alveolar defect that surgeons cannot reach without dissection of all its elements.

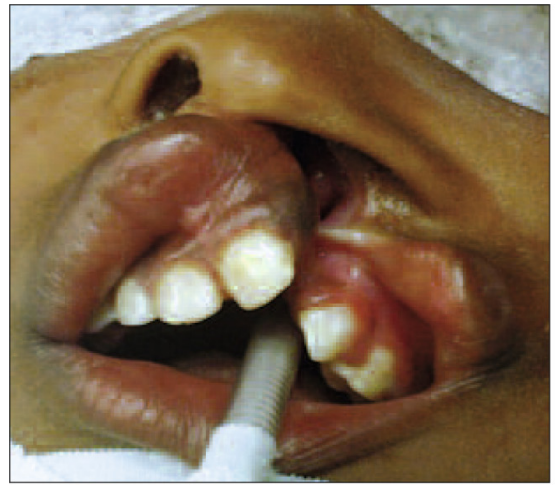

a

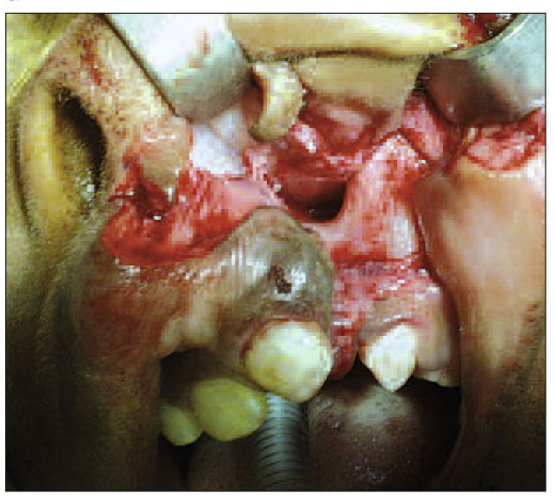

b

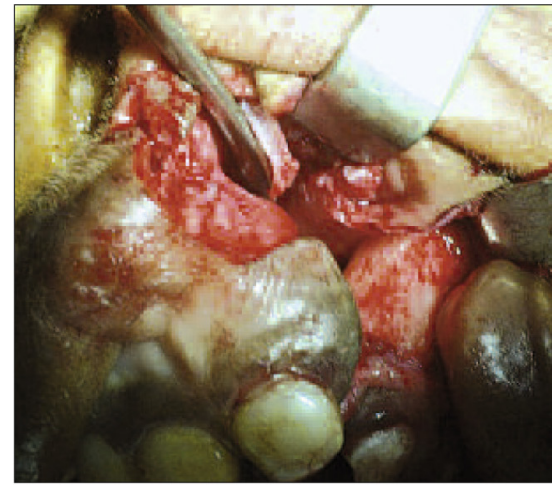

C

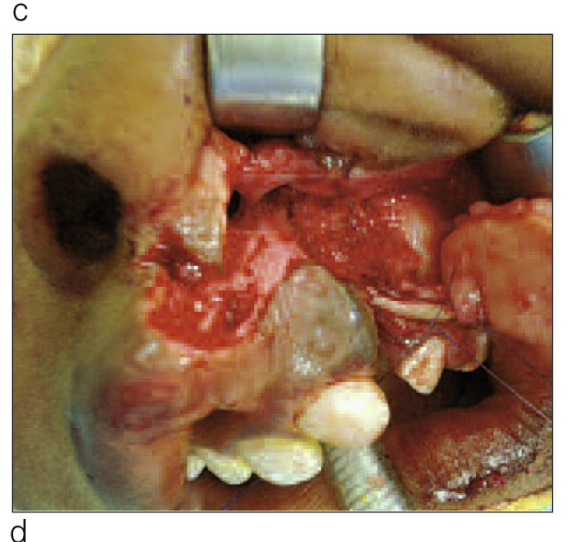

d

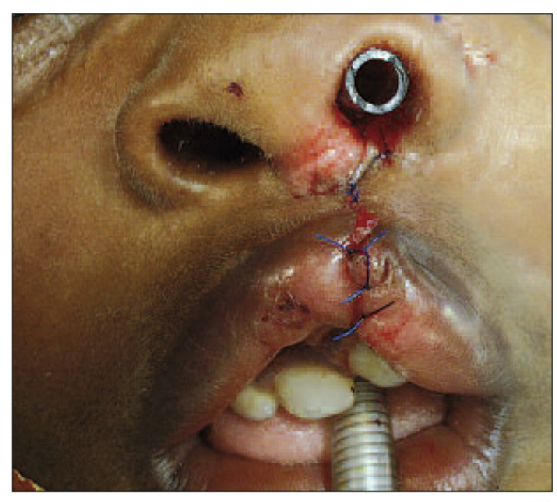

e

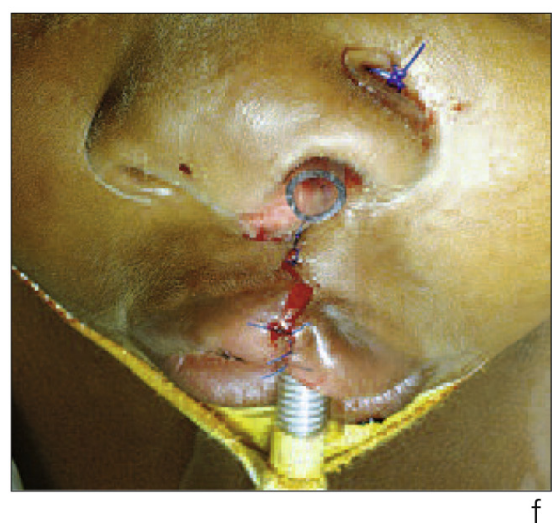

Figures 6a to $6 f$

Combined primary alveoplasty and cheiloplasty.

Serious labio-alveolar cleft. (a) view of the deciduous dentition. (b) Repositioning of the luxated nasal septum (c) alveolar graft. (d) labio-nasal correction. (e and f) improvised shaper. 


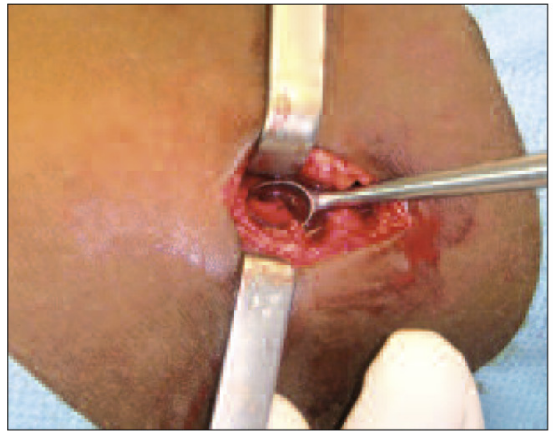

a

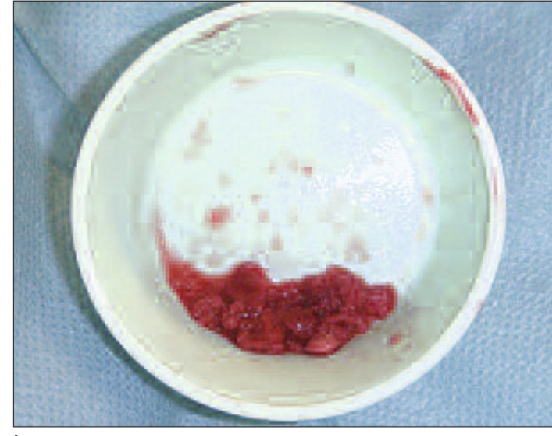

b

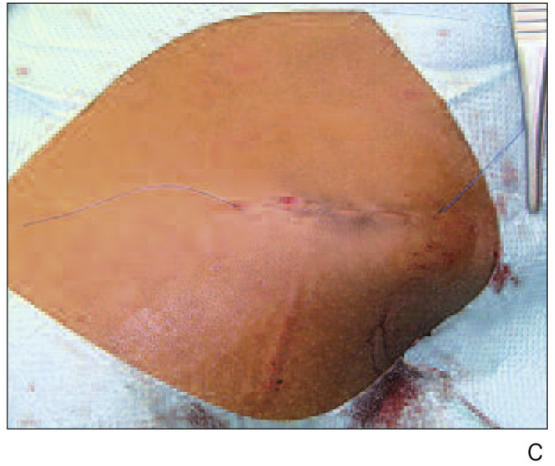

Figures $7 a$ to $7 c$

Harvesting osseous tissue for graft External iliac approach upper retractor exposes cartilage (a). Spongy bones shavings (b). Scarcely distinguishable residual iliac region scar (c).

Surgeons must treat complete bilateral clefts in two stages in order to preserve the viability of tooth buds in the midline. Surgeons must exhaustively revise and reconstruct all levels of the cleft, including the mucosal, muscular, and osseous as they perform a bone graft associated with a cheilo-rhinoplasty (Figs. 8 and 9) so that anatomic structures will be suitably repaired to support ultimate orthodontic treatment or surgical correction of protrusions.

In my practice I frequently see previously operated-on patients who refuse to accept needed orthodontic treatment so I have to compromise and find the best esthetic result that surgery alone can obtain.

\section{4 - 2 - Skeletal discrepancies}

\section{- Prevention}

Orthodontists can help surgeons prevent some skeletal discrepancies by skillful management of the osseous fragments of the dental arches both in the transverse and in the anteroposterior sense by widening the maxillary arch in the deciduous dentition with quad helices or rapid palatal expanders and with early secondary secondary alveoplasties with grafts. J.-C. Talmant and J.-P. Lumineau ${ }^{10}$, who now intervene on 3 year-old patients, have amply demonstrated the success of this procedure in formation of the dentition in allowing orthodontists to guide erupting teeth, including at risk laterals, into their proper positions.

However, no matter how sedulous follow-up care may be, not all operators and not all patients will obtain the same results owing, perhaps, to unfavorable growth or lack of harmony between upper and lower jaws. Relying solely on mandibular retraction and not performing maxillary advancement can lead to unacceptable compensations and increase of relapse. It is, in fact, the intervention of choice for avoiding undesirable sequelae because it stabilizes occlusion and offers incomparable esthetic benefits (Fig. 10) and, especially when associated with naso-labial "retouching", which in itself would not be able to provide hoped-for esthetic improvement based on a retruded maxilla (Fig. 11). 


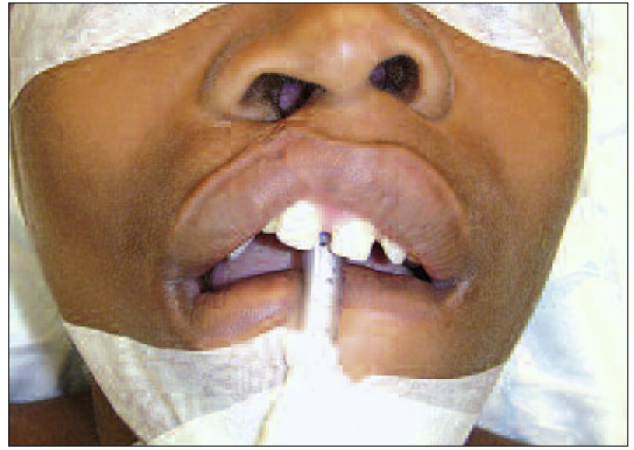

a

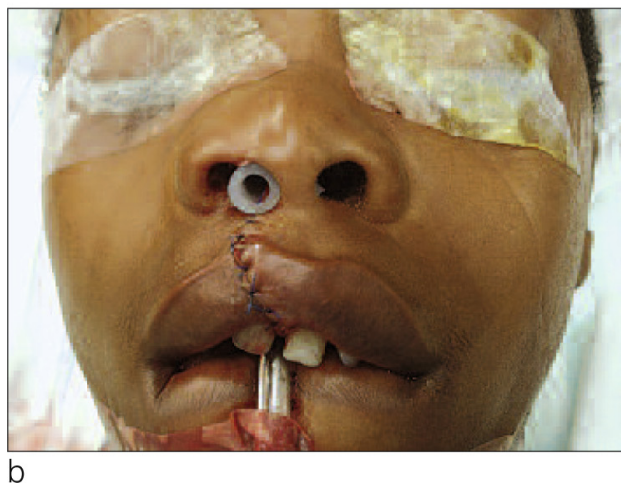

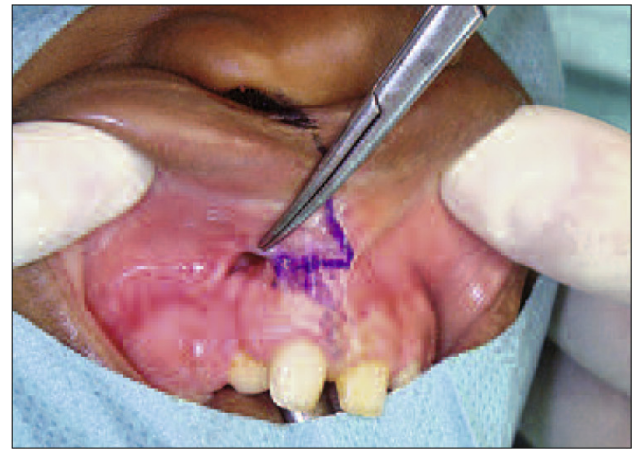

C

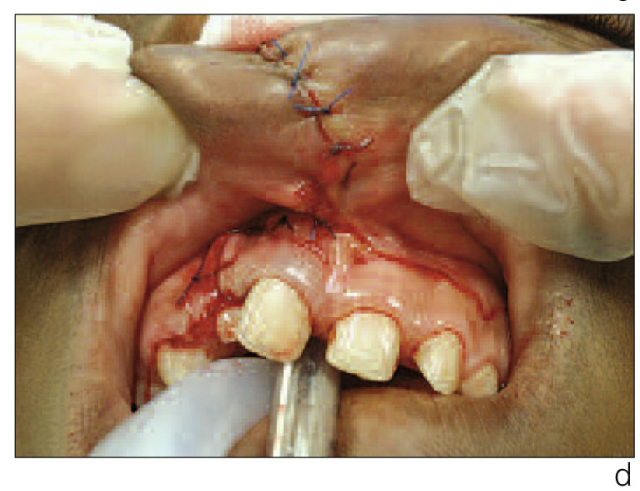

d

Figures 8 a to $8 d$

Treatment of an alveolar fistula.

(a) before (b) after (c) labio-nasal sequelae intra-oral view before (d) after gingivoplasty.

Surgeons should not, accordingly, hesitate to consult with the orthodontist about performing traditional preparatory treatment for a surgical "jumping the bite" procedure at the close of the growth period.

Finally in this connection, it should be said that osteo-distraction technique can be an extremely useful addition to early orthodontic and orthopedic treatment. Trousseau ${ }^{6}$ and other teams employ this procedure that I learned of during a course with F. Ortiz-Monastero in 1994, with great success. Unfortunately it is not suited for isolated practices like mine so I have had to rely on more conventional orthodontic-surgical ap- proaches for patients with impaired skeletal growth.

\section{- Treatment of basal bone discre- pancies}

This cooperative orthodontic and surgical correction follows classic principles of orthognathic surgery with orthodontic preparation of one or both arches for ultimate maxillo-facial intervention but is adapted to the individual needs of the cleft palate patient.

\section{- Surgical adaptations}

Because anatomic defects of the maxillary arch and the palate caused by the osseous cleft badly or not at all repaired will interfere with maxillary dissection in the nasal area in the final surgery, it is important to complete 


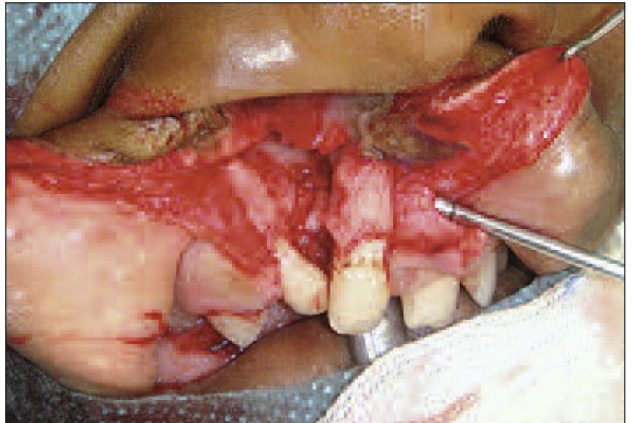

a

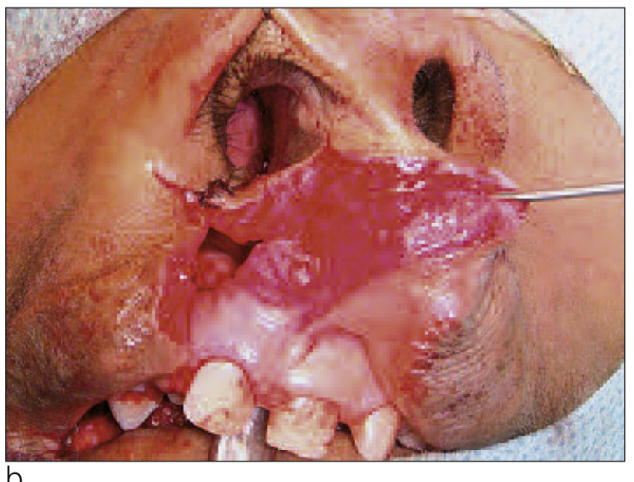

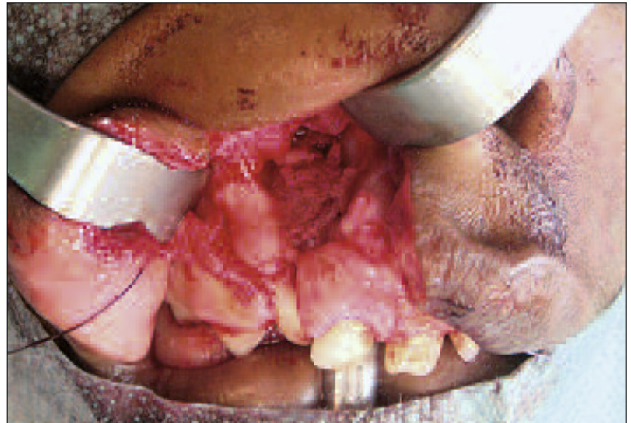

C

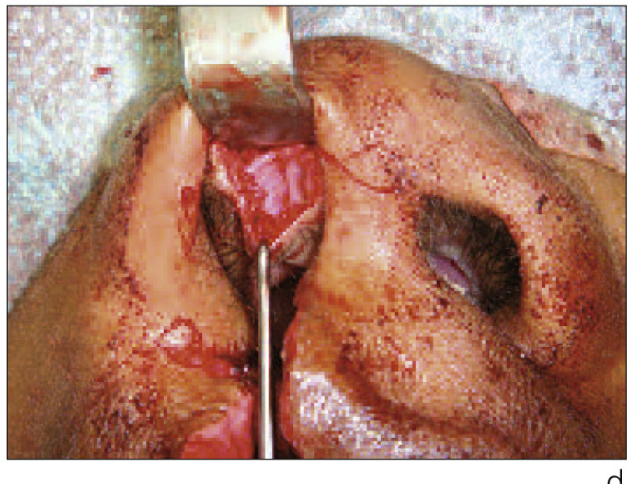

Figures 9a to $9 d$

Details of the procedure.

(a) complete dissection up to the retro-alveolar zone (b) reflection in nasal area (c) alveolar graft (d) nasal stage of the cheilo-rhinoplasty, dissection of the wings.

the alveoplasty and orthodontic alignment of the arch beforehand. Surgeons must be aware that local conditions with cleft patients make intervention more delicate than it is in routine orthognathic procedures with the pitfall situated less in the transverse sense, where orthodontic therapy will have dealt with the problems of asymmetry, than it is with anteroposterior advancement restricted by scar tissue formation. This advancement is also constricted by the need not to aggravate, or actually reveal, lack of soft palate pharyngeal seal. Rather than risk this complication where there is any uncertainty, a mandibular osteotomy should be performed. This also confers the benefit of lowering the risk or maxillary relapse caused by poor bone quality, instability of osteo-synthesis and occlusion. In such cases maxillary bone may appear stunted, poorly vascularized, badly ventilated, and too fragile to support stable occlusal interdigitation. These failures could lead to relapse and a need to repeat the orthodontic-surgical procedure, which would be as distressing for the treatment as it would be for the unfortunate patient.

None of this means that maxillary advancement surgery for cleft patients should be abandoned because it is uniquely beneficial for cleft treatment from both occlusal and esthetic standpoints. But it does mean that 

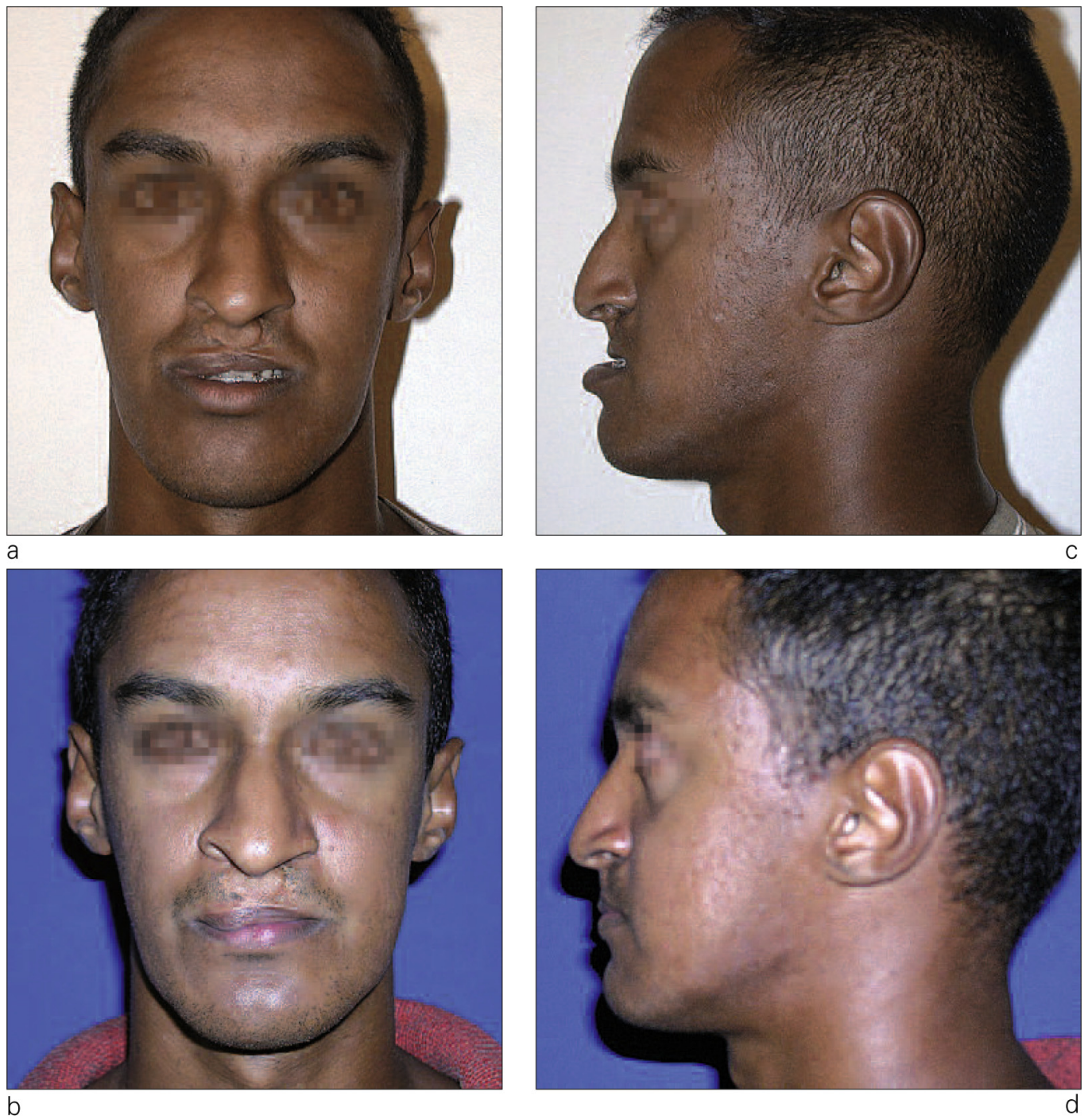

Figures 10a to 10d

Aesthetic improvement achieved by maxillary advancement.

Bimaxillary surgery to correct mandibular prognathism and maxillary retrusion

Before and after full-face views ( $a$ and $b$ ) and profile views (c and d). Note how lip competence has been regained by a lip repair that could still be further improved.

surgeons should be fully cognizant of the risks involved before intervening (Figs. 12 and 13).

- Special occlusal conditions

All team members have their roles to play in this stage of resolution of sequelae problems. The orthodontist will arrange the upper and lower teeth in as close to ideal occlusion as the missing element will permit. Even in the most prosperous of our island communities most patients have not had the pediatric dental care that prevails in metropolitan areas 


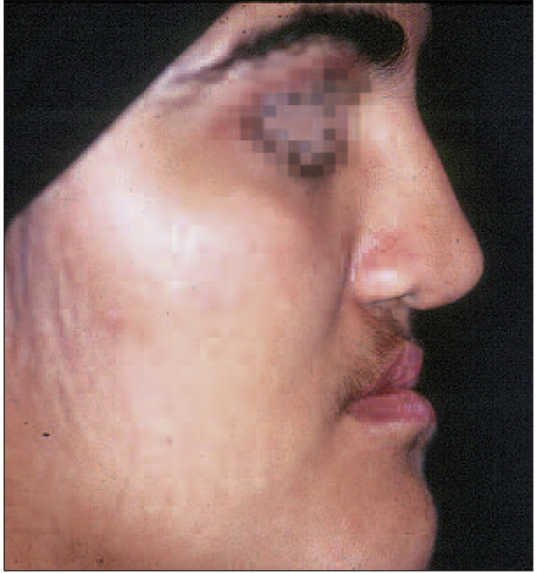

a

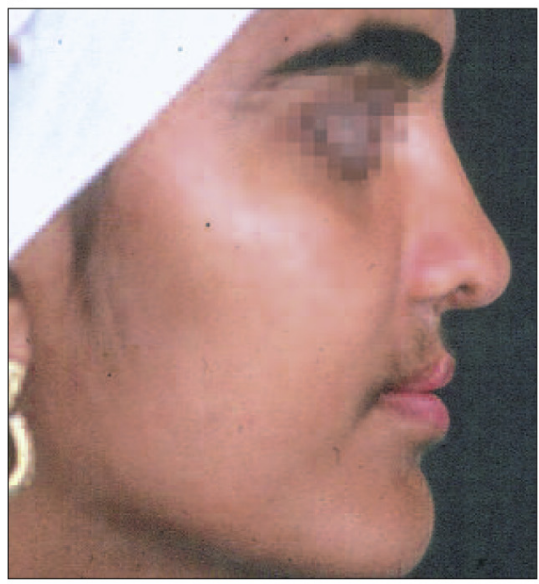

b

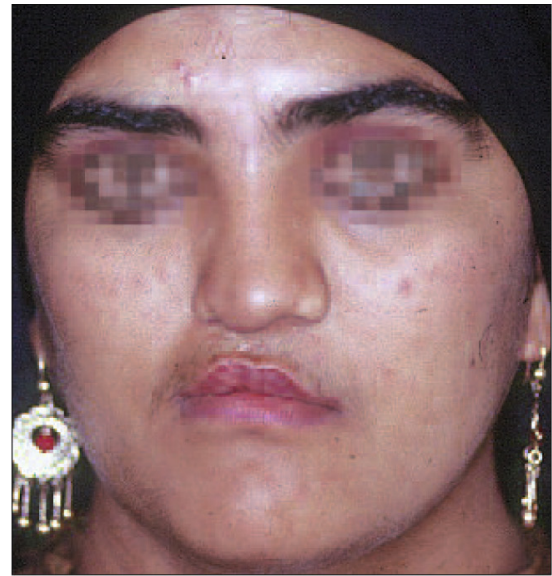

C

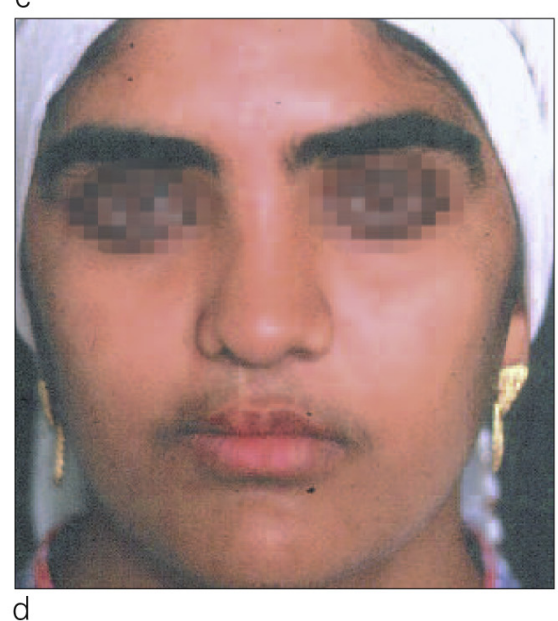

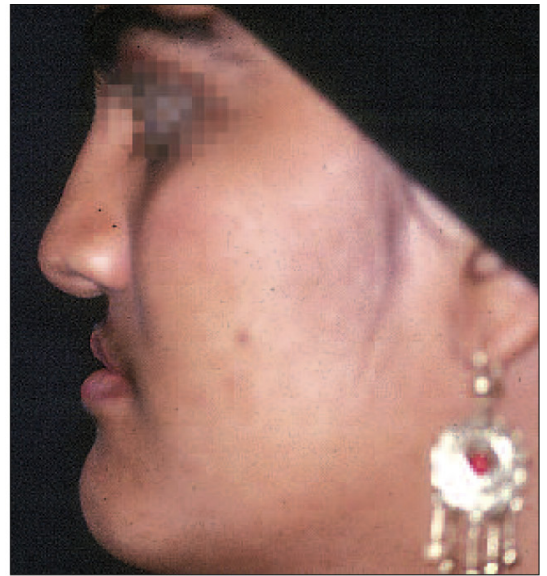

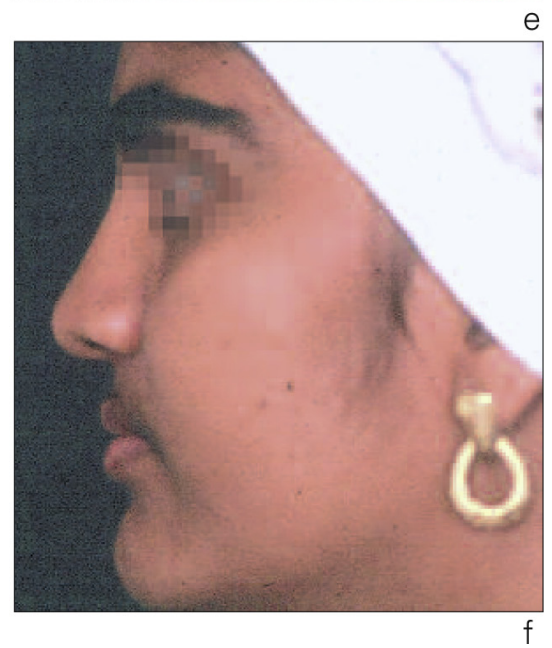

Figures 11a to $11 f$

Aesthetic labio-nasal gains with maxillary advancement.

Before and after photos of patient who had two-stage surgery, right profile, full face, and left profile. Persistence of moustache is a distraction.

(Figs. 14 and 15). Very few adult cleft palate patients, particularly those who have congenitally absent upper laterals, have symmetrical arches. In accordance with the treatment plan spaces must be opened or closed within the limits of what is reasonably possible in terms of existing dental and skeletal conditions. At this point I think it is appropriate for me to pay homage to my friend Dr. Bernard Dumoulin, a distinguished orthodon- tist working overseas whose skill and occlusodontic approach is especially adapted to cleft palate treatment where occlusal compromises are so often needed. He uses intercuspation splints made by technicians on models mounted on articulators to stabilize the inter-arch relationship for two stage bimaxillary surgery as a substitute for the intercuspation of teeth that is highly unreliable before osteosynthesis is completed. 


\section{5 - LABIO-NASAL SEQUELAE}

Plastic surgeons who treat cleft palate patients find that the nose and lips are the areas school age patients and parents most frequently ask them to correct because of the social deficit they impose. These sequelae appear in two forms depending on the extent they affect the maxilla. It should be remembered that resolution of nasolabial clefts is an essential preparation for repair of nasal and labial soft tissue whose isolated dissection can be undertaken only for benign labial or labio-alveolar clefts, those where separation of segments of any kind is present and no occlusal discrepancy has occurred. The designation benign cleft also signifies that no ultimate lip or nose esthetic surgery will be needed.

\section{5 - 1 - Labio-nasal-maxillary sequelae}

The imbalance of the height of their upper lips with shortness on the side of the cleft usually accompanied by a nasal deformity is the chief facial malformations that assault the self esteem of cleft palate patients. These defects mask the underlying reality of an incomplete maxilla. Surgeons reshape the face with a combined gingivo-chili-rhinoplasty adapted to the age of the patient and the overarching centro-facial reconstruction strategy. This may be a complete reconstruction of the maxillary arch combined with columellar elongation in two stages for a bilateral cleft (Figs. 16 and 17, or limited to the red part of the lips above the vermillion border (Figs. 18 and 19) or to its
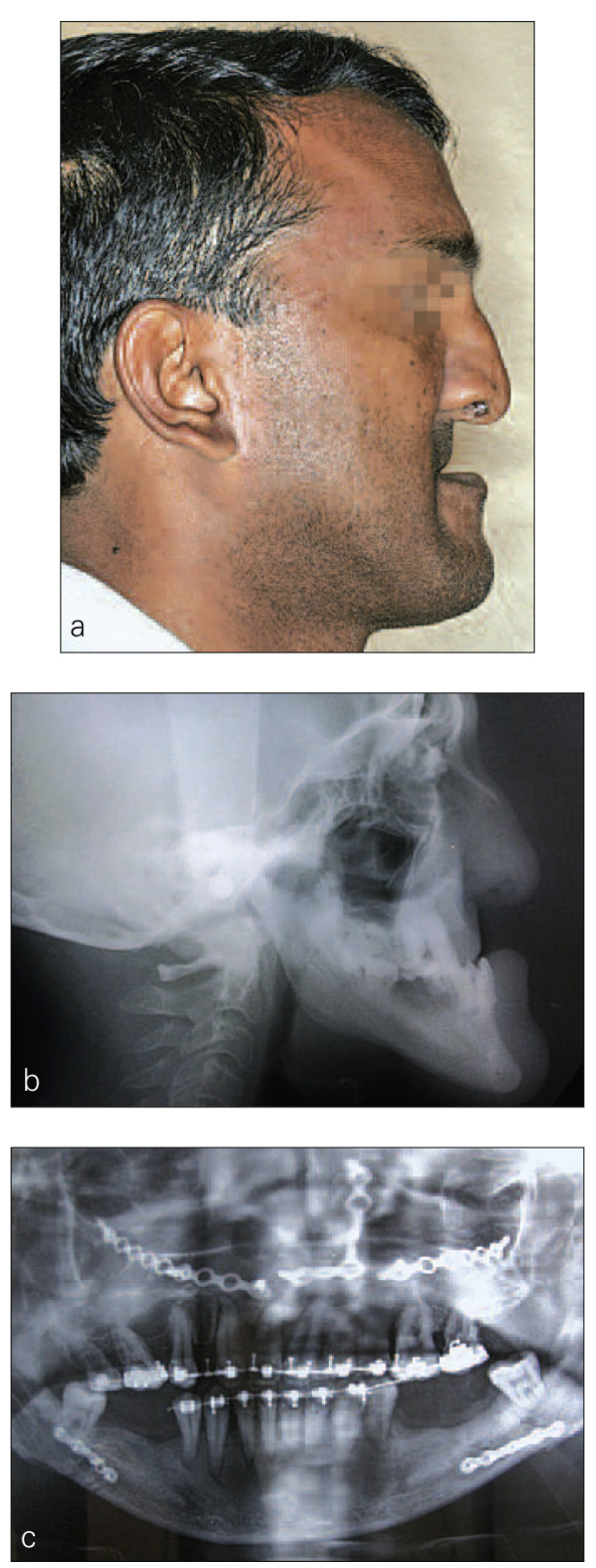

Figures $12 a$ to 121

Post-autopsy photos of an (extremely) grave relapse.

buccal surface (Fig. 20) and then associated with a dissection of the wing of the nose ${ }^{9}$ assisted by obligatory wearing of a shaper for four months as is done in primary cleft surgery. It can be impossible to restore the premaxillary region 

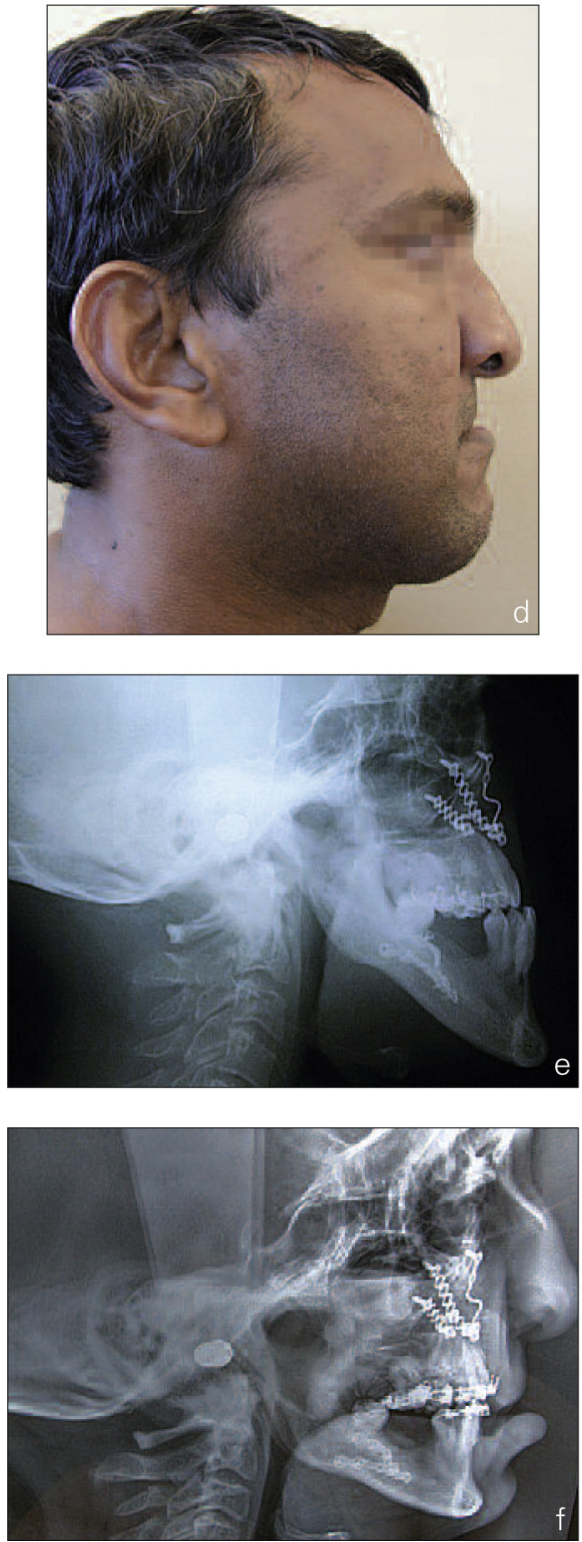
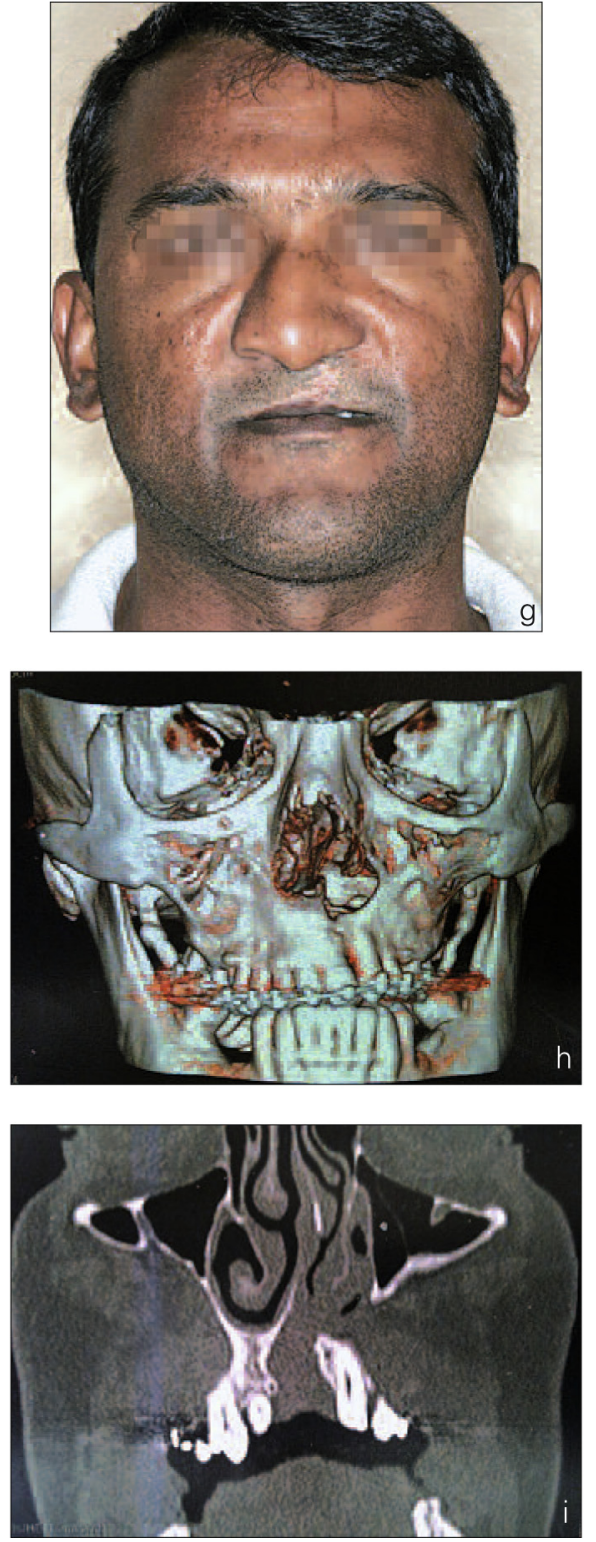

This patient, who had a severe mandibular prognathism $(a, b)$, well corrected $(c, f)$, suffered a severe relapse $(d$, e) because, at least in part, of an unstable maxilla with insufficient anterior alveolar process. Osteosynthesis, which did not get well established ( $k$, l, was unable to resist secondary maxillary retraction. We had certainly improved this patient's appearance to some extent, but his disappointment with the partial result can be read in his visage $(g, j)$. 

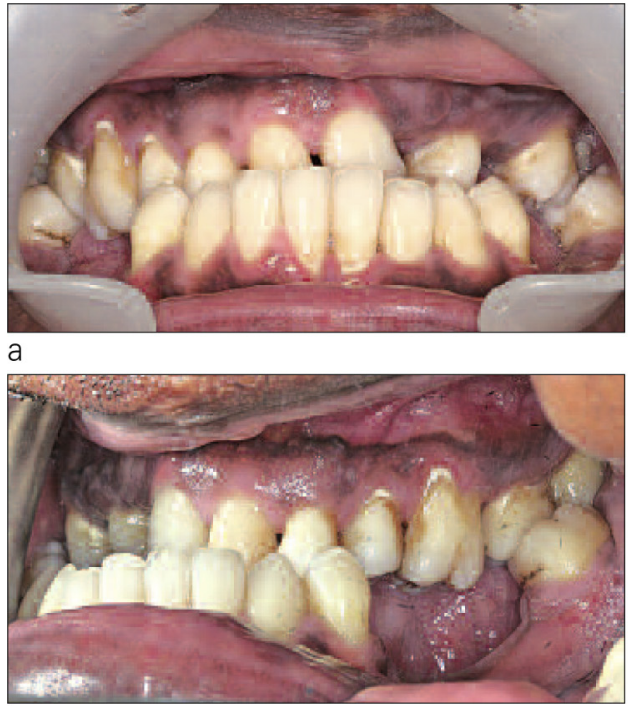

$\mathrm{b}$
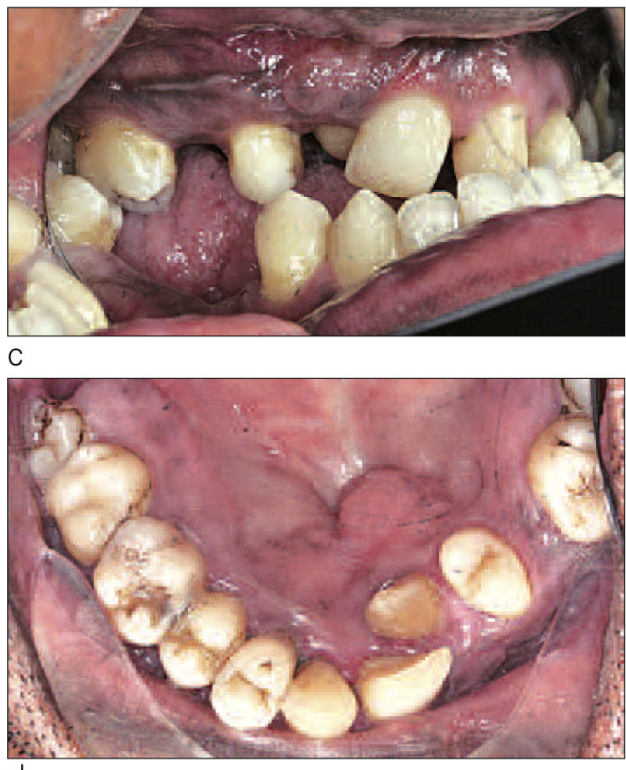

d

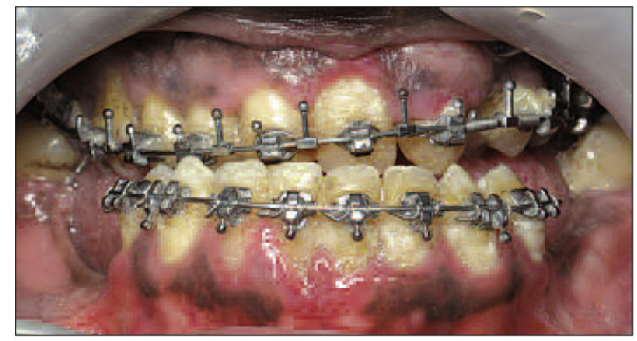

e
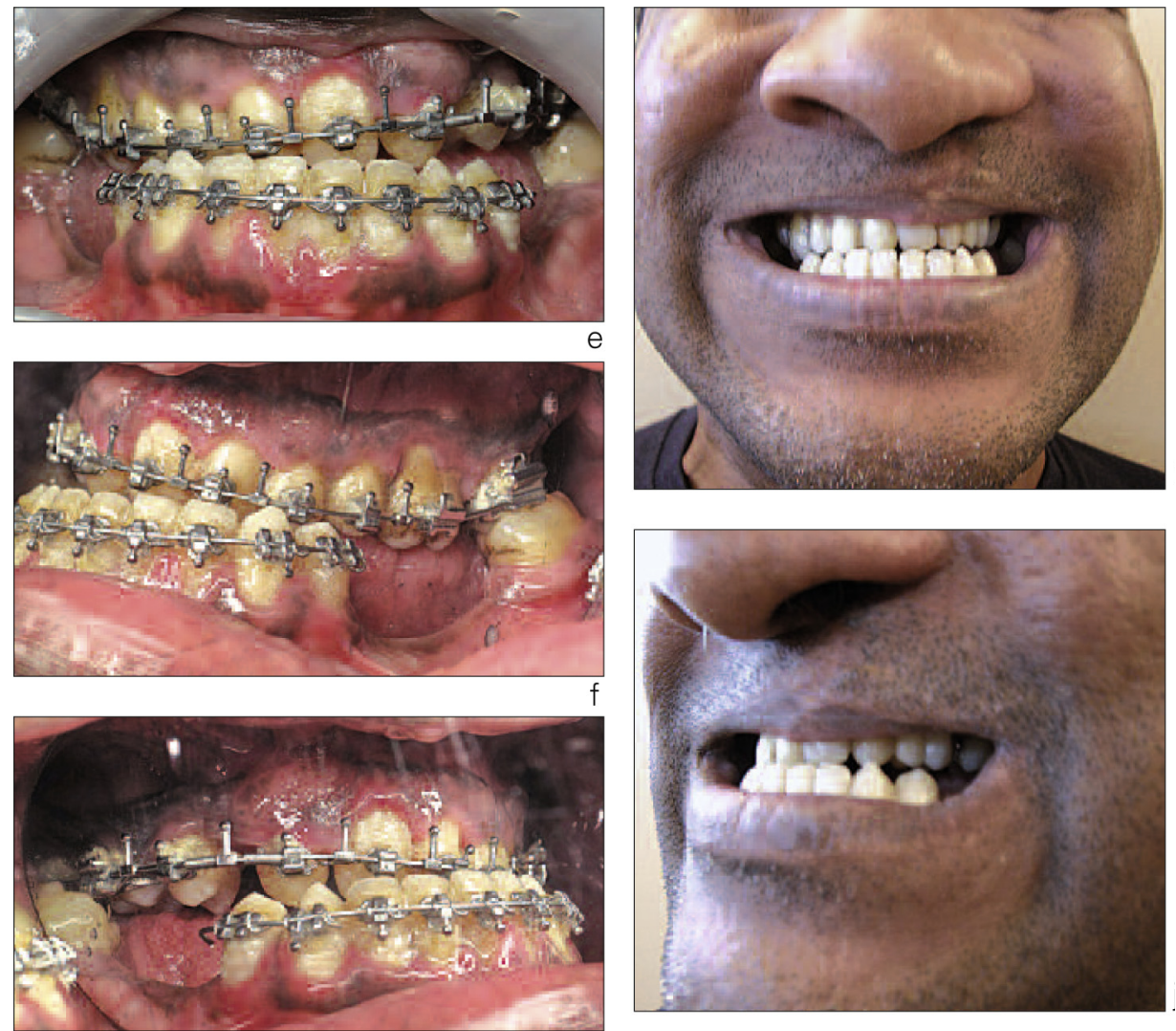

.

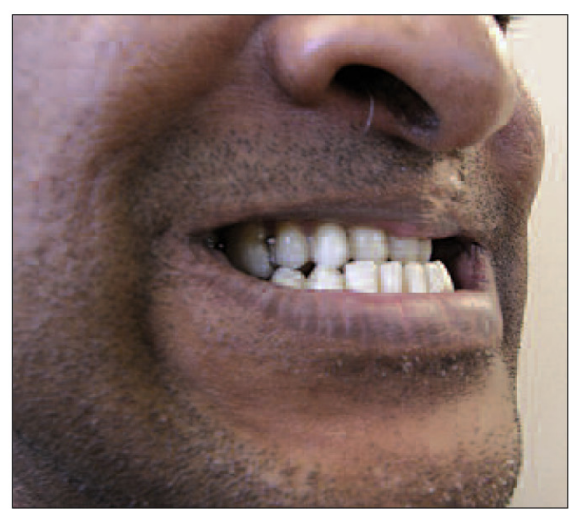

Figures 13a to $13 k$

Intraoral and facial photos of patient depicted in figure 12.

He had too few upper anterior and lower molar teeth $(a, b, c, d)$ making it difficult for the orthodontist to achieve a compromised but stable occlusion that would prevent return of the mandibular protrusion. Unfortunately, the accumulation of unfavorable factors made this impossible. 


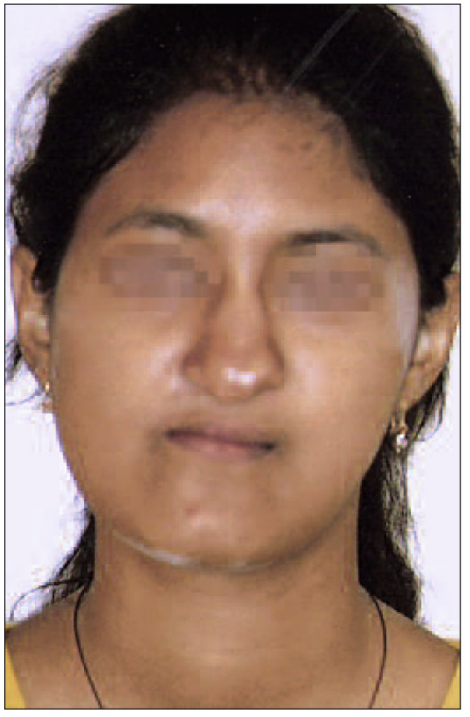

a

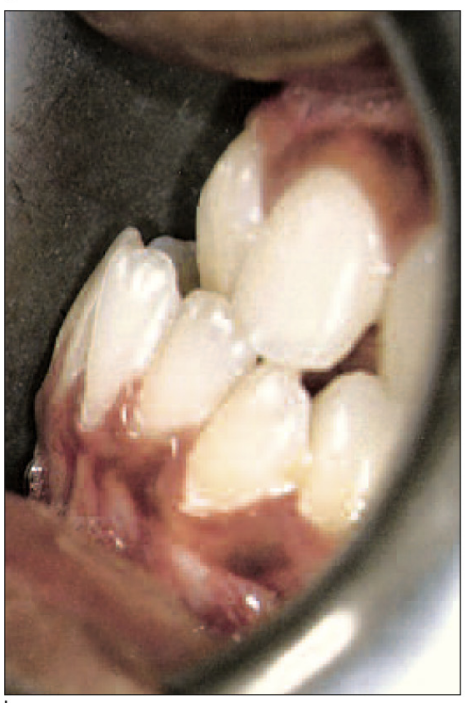

b

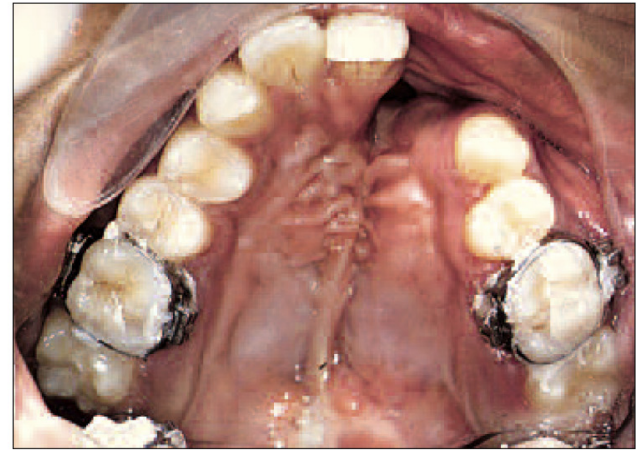

C

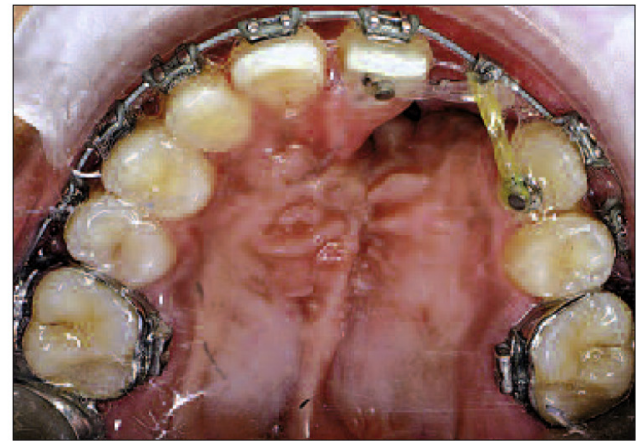

e

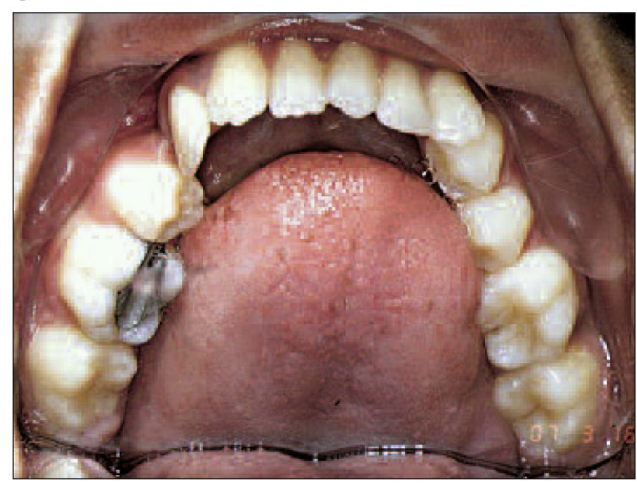

g

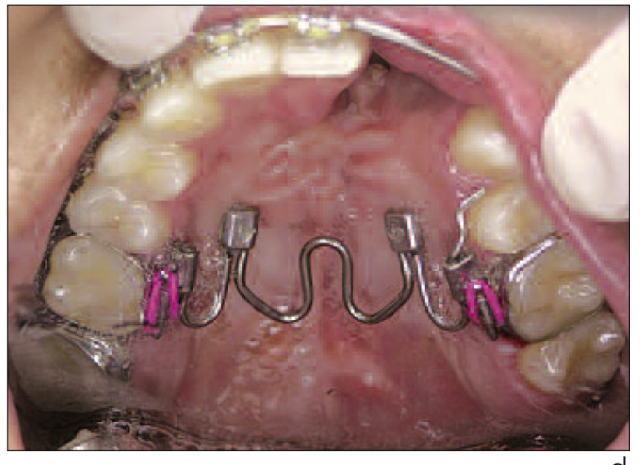

d
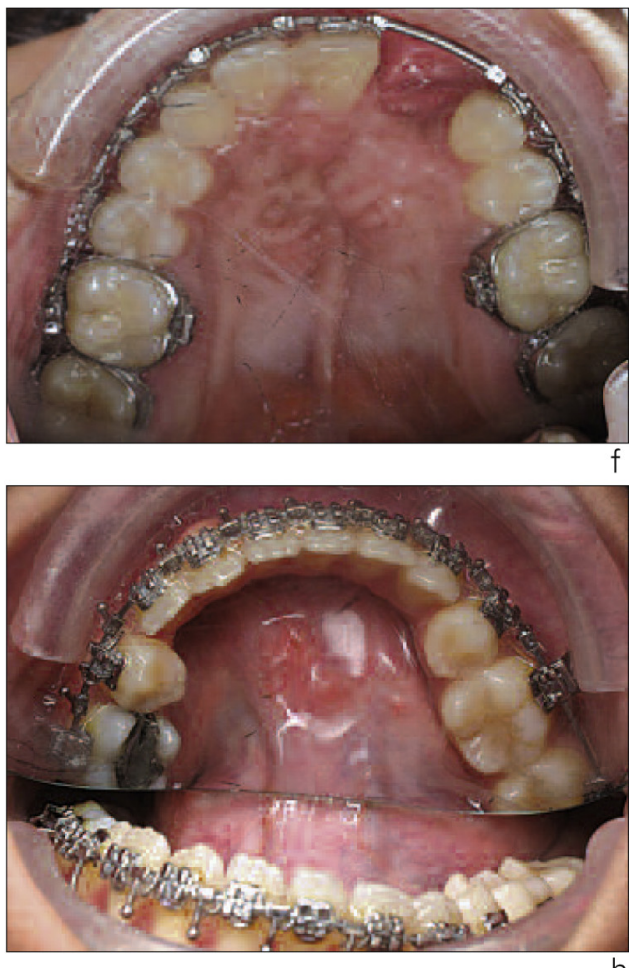

h

Figures $14 a$ to $14 h$

Orthodontic preparation for a bone graft and occlusal surgery.

This young woman from the Island of Mauritius who had a unilateral Class III malocclusion, (a and b) had the good fortune of consulting Doctors B. Dumoulin and J. -C. Talmant. Her therapy, which began at the close of the growth period, consisted of initial orthodontic preparation and separate stages of a maxillary bone graft with the usual expansion procedures ( $c, d, e$, and f), and then symmetrical alignment of the upper and lower arches ( $g$ and $h$ ). (Note: these intraoral photos were taken with a mirror. The cleft is still on the right.) 

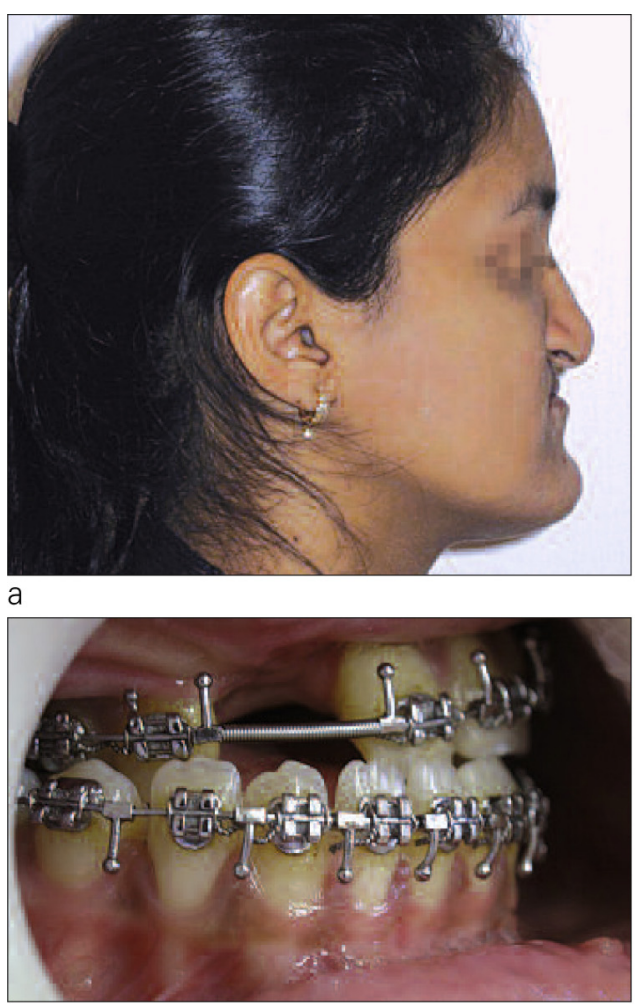

b

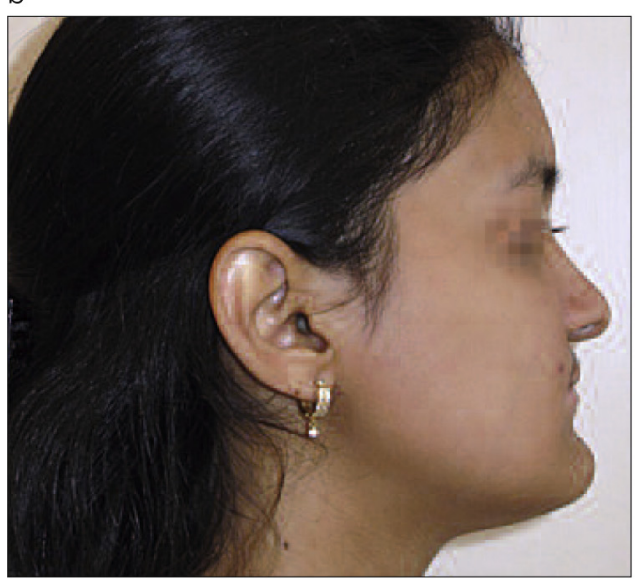

C

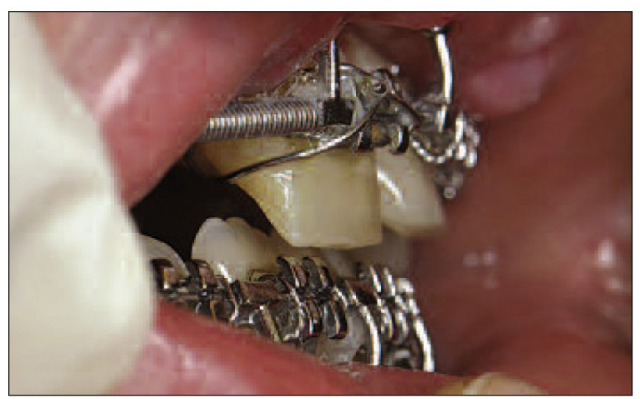

d
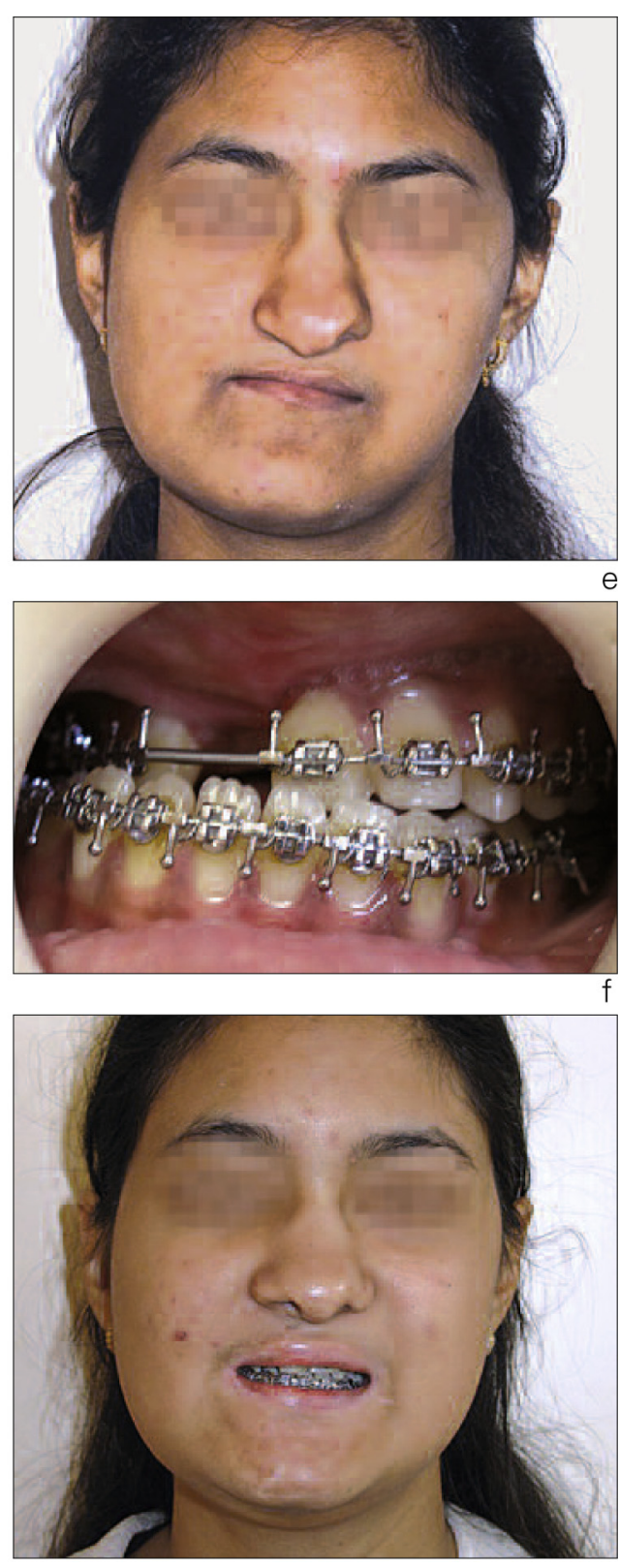

g

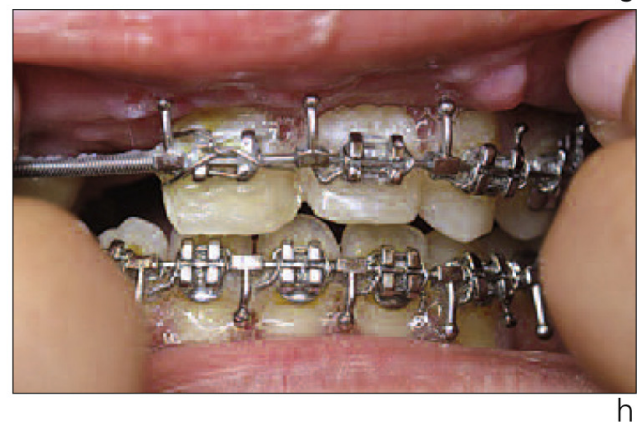

Figures $15 a$ to $15 \mathrm{~h}$

Result of the bimaxillary occlusal surgery for this young Mauritian woman. Before and after profile views $(a, b$, $c, d)$ and full face $(e, f, g, h)$ show facial appearance and provisional occlusion. 

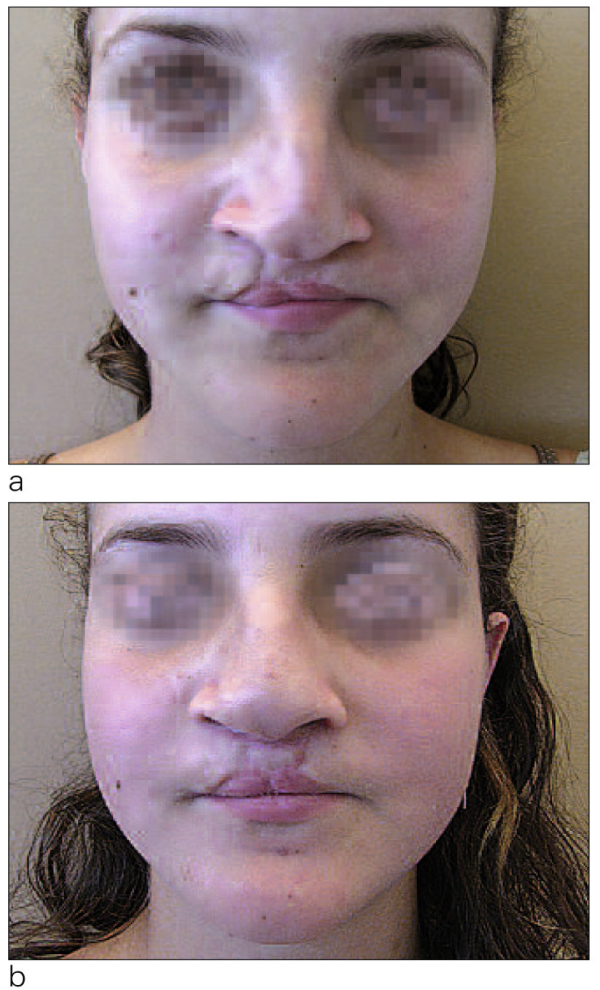

$\mathrm{b}$

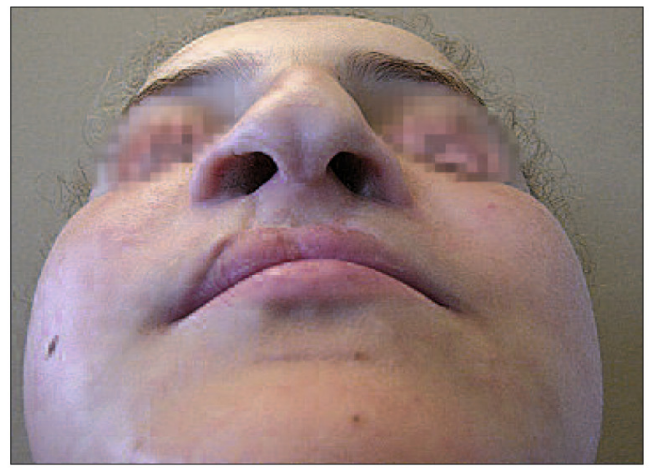

C

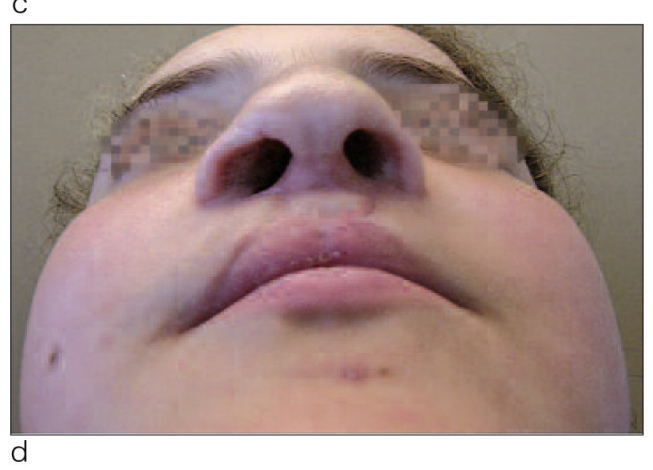

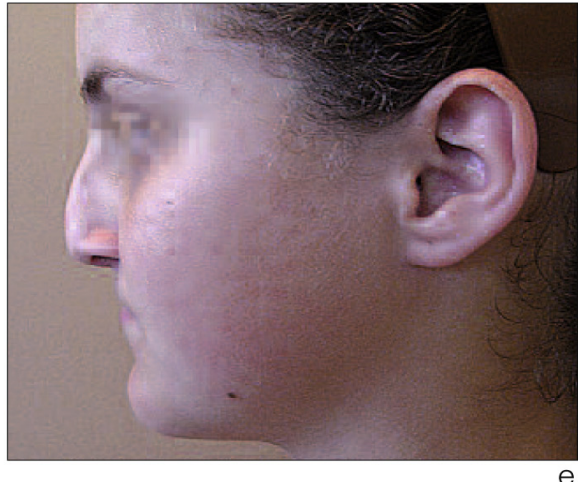

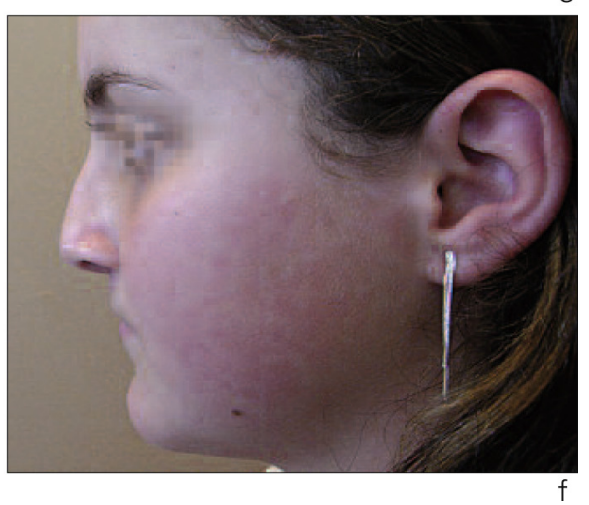

Figure 16a to $16 f$

The nasal deformity is predominately on the left side with a shortened columella continuous with the philtrum (a, c). Surgery has improved lip height and the base of the nose $(b, d)$, and the projection of the columella $(e, f)$ to ameliorate the patient's profile. Further improvement of the right side of the nose can be achieved with a final rhinoplasty.

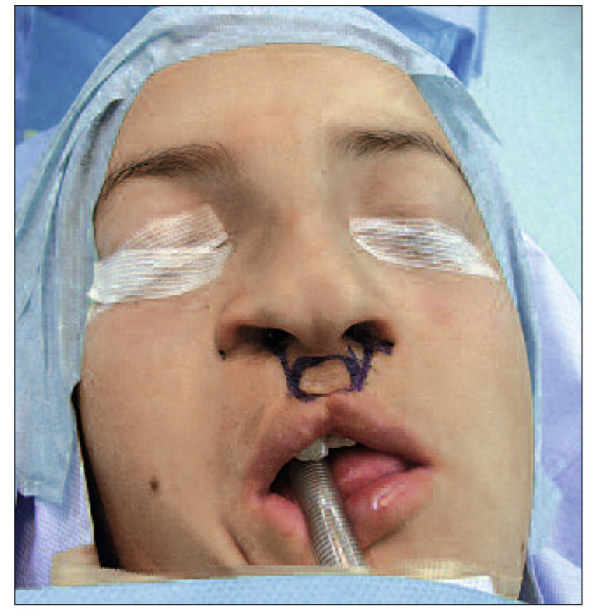

a

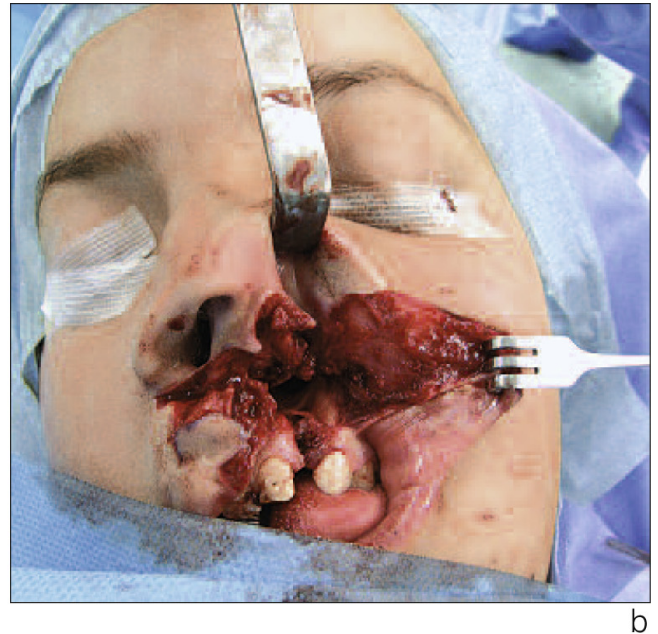

b

Figures $17 a$ and $17 b$

Photos of operation to repair base of nose. Surgeon laid back a Millard forked pedicle flap from the philtrum to the corner of the lip (a) then completely dissected the cleft (b) in preparation for a gingioplasty with bone graft on the prepared osteo-cartilagenous structures of the nose. 

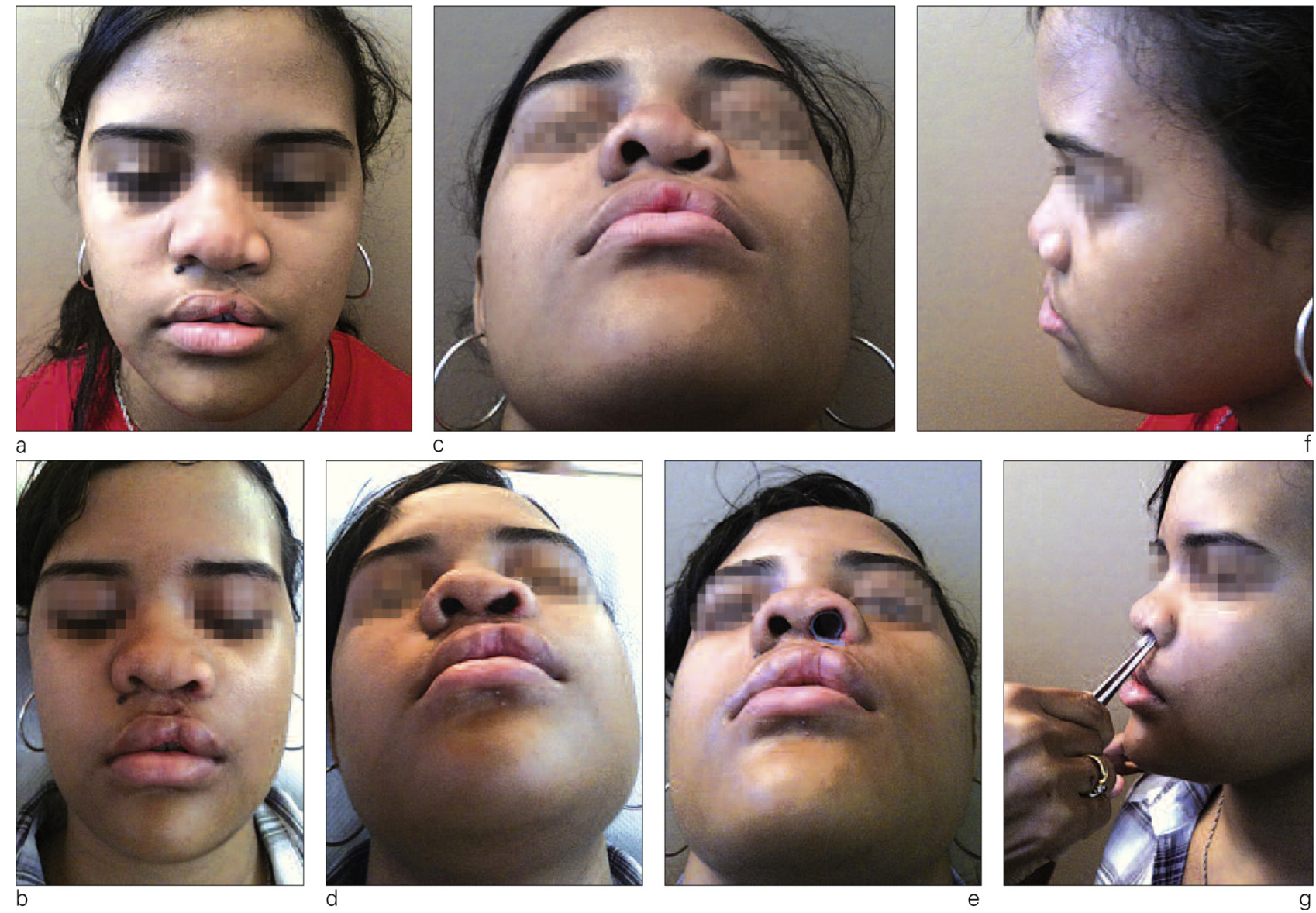

Figures 18a to $18 \mathrm{~g}$

Secondary rhinoplasty to correct unilateral sequella. Patient was eager to achieve appearance of her nose with its extremely thick tissues that required her to wear a conformateur $(c, d, e)$ full time post-operatively for that she removed only to preserve good hygiene ( $f, g)$.

anatomically either for technical reasons (Fig. 21) or because of patient's refusal to undergo the procedure.

\section{5 - 2 - Isolated labial sequelae}

\section{- Anomalies of white lips}

These appear either as a result of severe clefts affecting the maxilla or because of some fault in primary treatment of a more innocuous cleft. The latter defects should be repaired well enough to obtain a symmetrical arch in Cupid's bow shape.

\section{- Reconstruction of the philtrum}

In my view only an Abbe-Estlander hetero-labial flap ${ }^{8}$ is completely effective in restoring the philtrum. Total skin grafts are too visible, as can be seen in this patient with overly pale, smooth skin interrupting the continuity of his moustache. He had a two-stage procedure consisting of taking from the lower lip what the upper lip needed for repairing its scar-provoked 

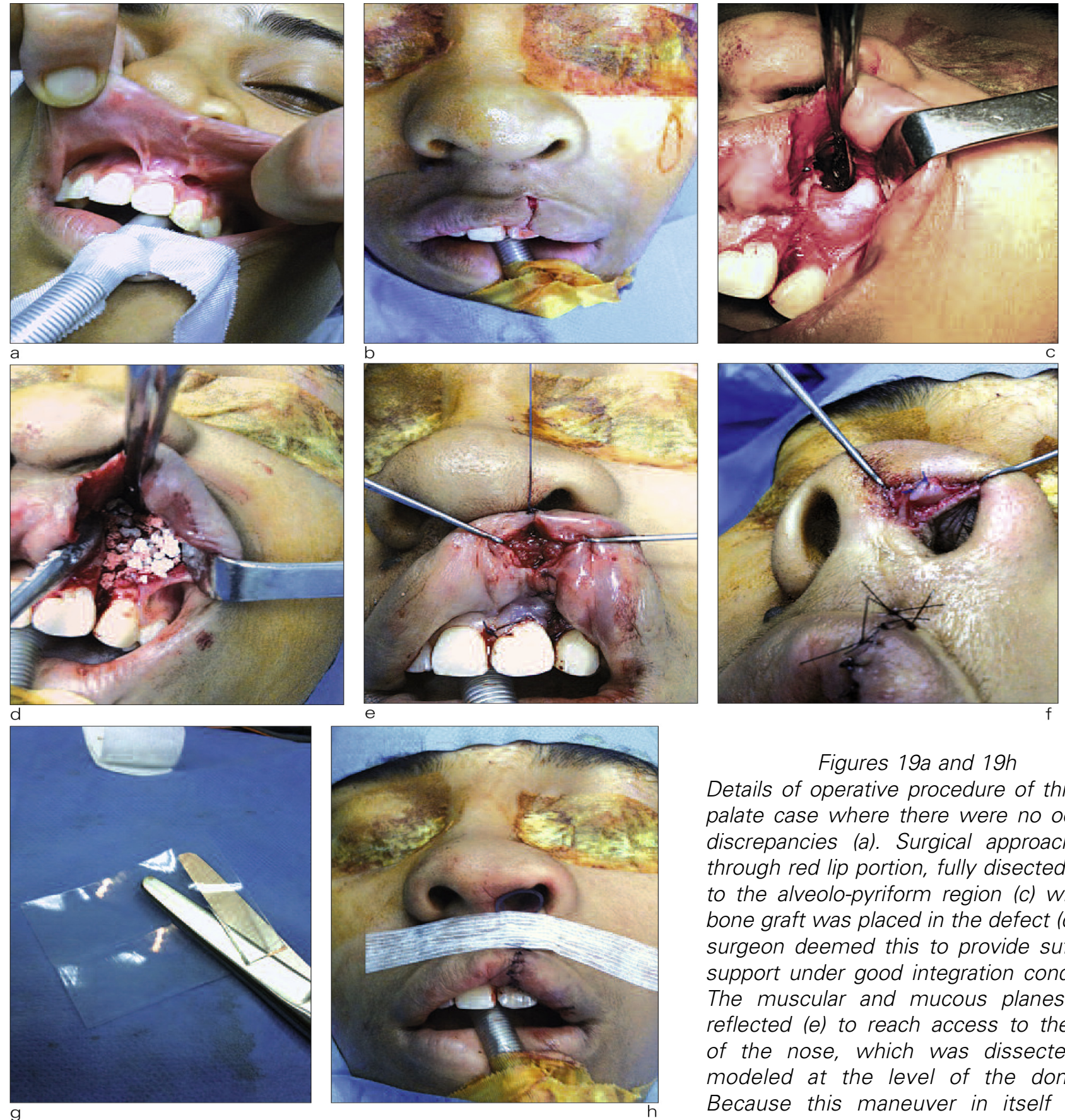

Figures 19a and 19h

Details of operative procedure of this cleft palate case where there were no occlusal discrepancies (a). Surgical approach was through red lip portion, fully disected (b) up to the alveolo-pyriform region (c) where a bone graft was placed in the defect (d). The surgeon deemed this to provide sufficient support under good integration conditions. The muscular and mucous planes were reflected (e) to reach access to the wing of the nose, which was dissected and modeled at the level of the dome (f). Because this maneuver in itself is not sufficient to fully plump out the nostril, the patient will wear a standard shaping device in a sheet of of Silastic (g) attached to the lip by an adhesive strip (h). 


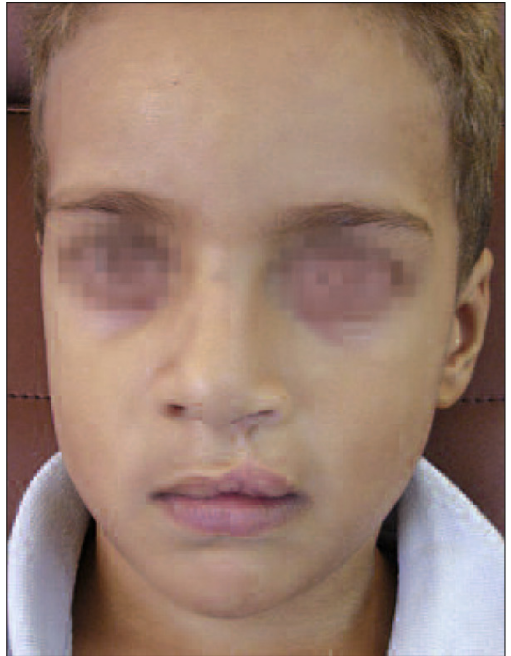

a

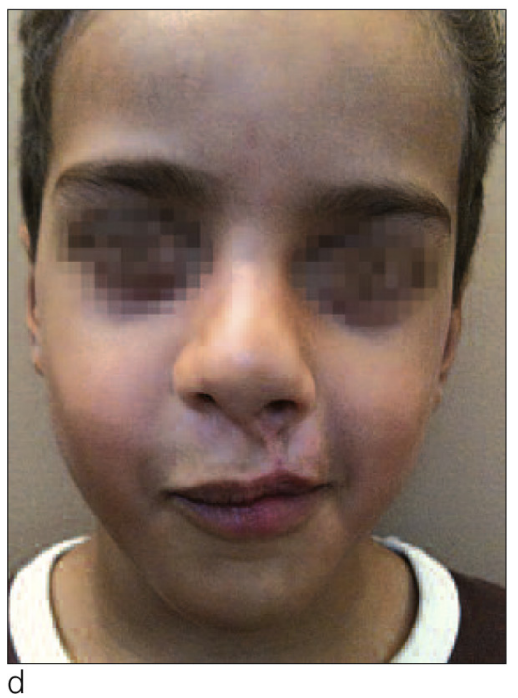

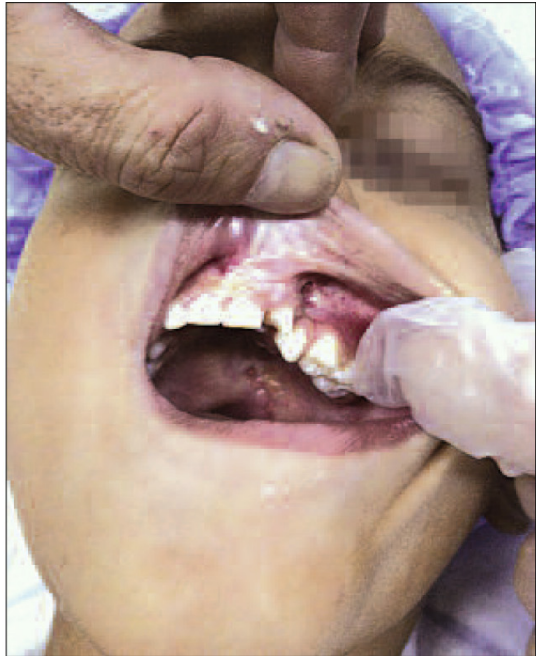

b

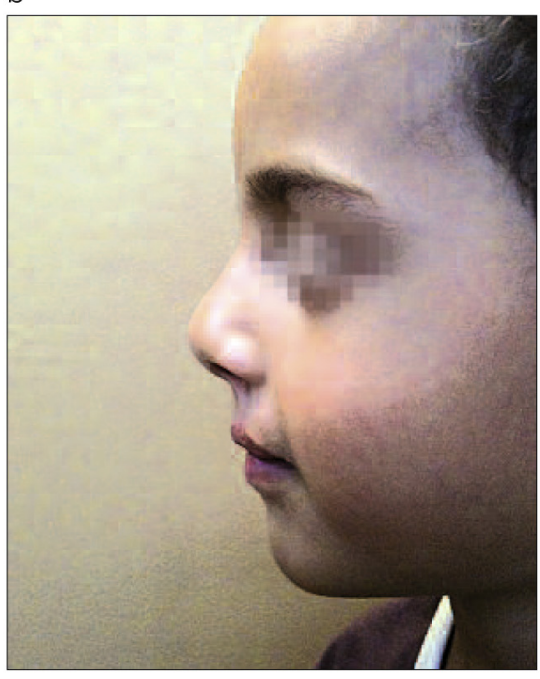

e

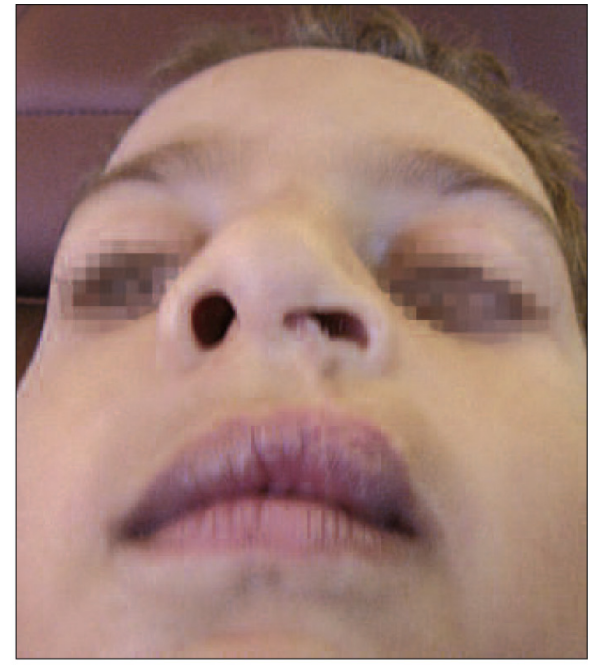

C

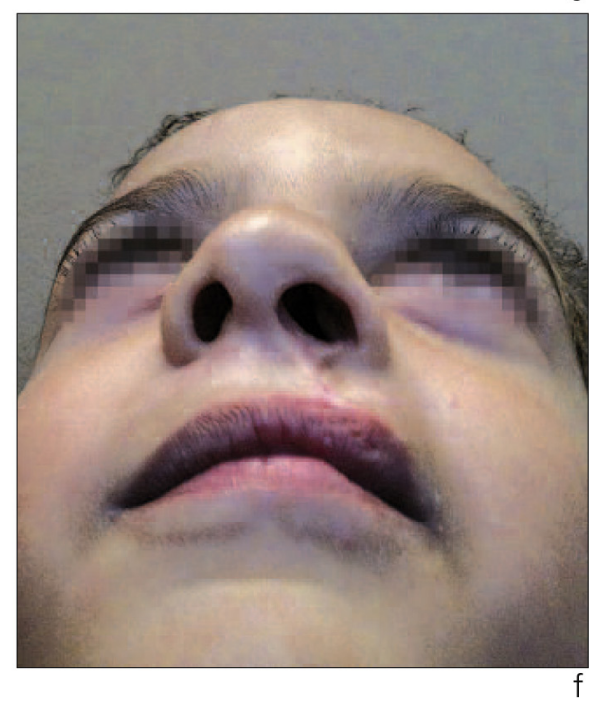

Figures 20 a to $20 f$

Facial views of secondary partial cheilo-rhinoplasty.

This patient had a labio-palatal cleft $(a, b)$ that required an alveoloplasty after orthodontic preparation. But because of the difficult situation and the limited need for nasal repair, the procedure was limited to the buccal sector by placement of an alveolar graft, harvested from the ilium that improved the height and plumpness of the lip without actually touching them (d). The wing of the nose was dissected so the nostril could receive a shaper. Before (c) and post-operative views $(e, f)$. A superficial adjustment of the white lip and of the base of the nose still needs to be made.

constriction (Fig. 22). But to preserve the appearance of the lower lip the surgeon's removal of tissue must be discreet.
- Correction of asymmetry in red portion of lip, in thickness or placement of free ends. 

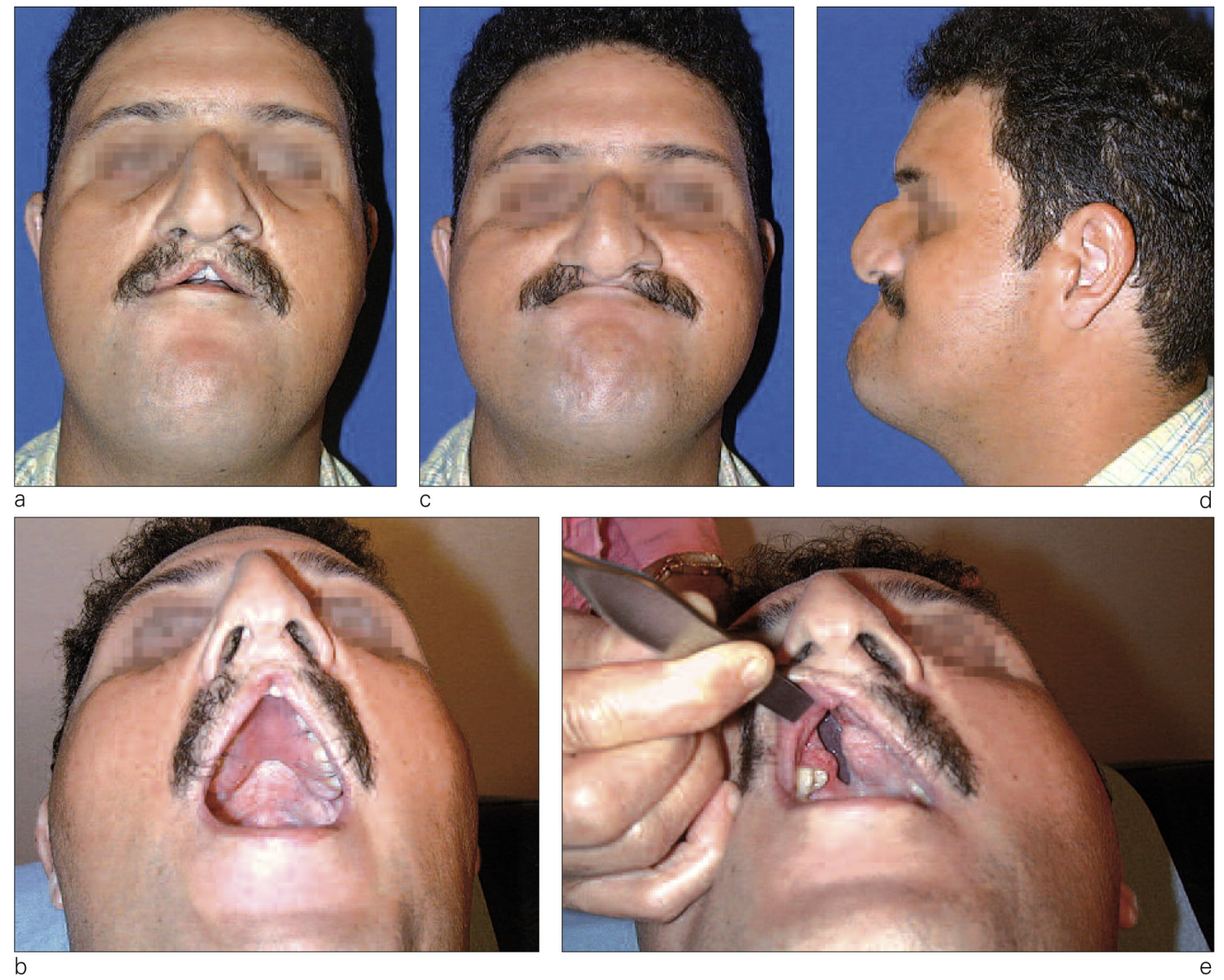

Figures 21a to 21 e

Necrosis of the pre-maxilla therapeutic impasse.

Perhaps the worst type of sequella affected this patient's treatment. A victim of inappropriate initial treatment of his nose, he could not understand why complex labio-maxillary surgery was still needed. Above facial photos. Below open mouth with prosthetic plate in place (b) and without plate (e.)

These procedures can be undertaken only when the white lip is symmetrical and totally in place. They are frequently required even when the cleft does not affect the maxilla. The cheek area may not be deep enough or somewhat engulfed in the case of bilateral clefts. The procedure is more difficult than it might appear, fully testing the operator's skill and experience because other muscular and dermal areas may be involved. I have sometimes had to use filling material to gain sufficient plumpness in lip 


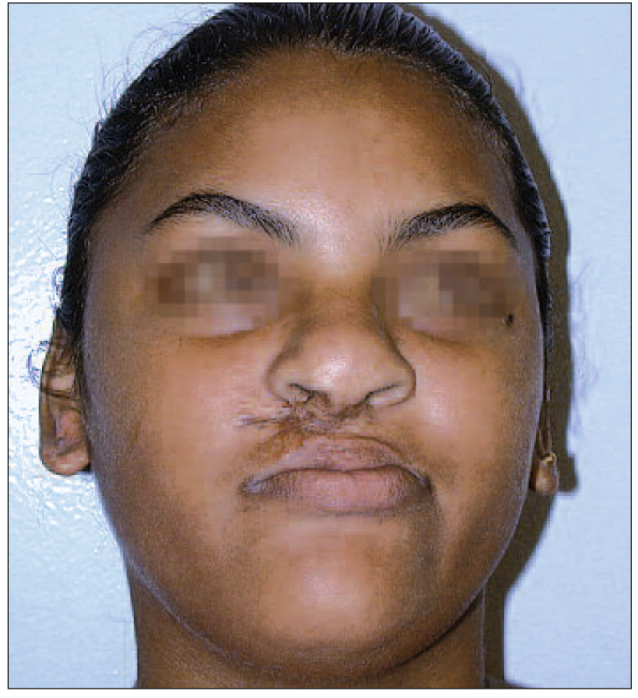

a

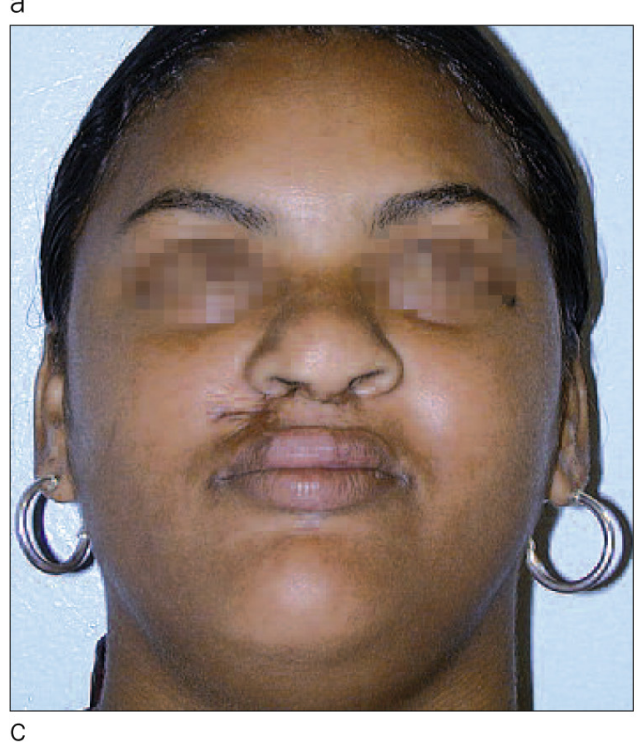

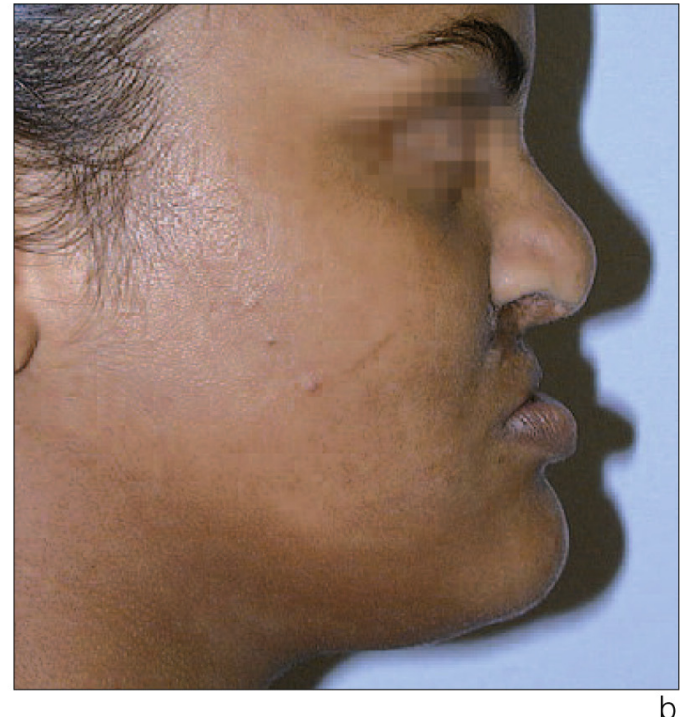

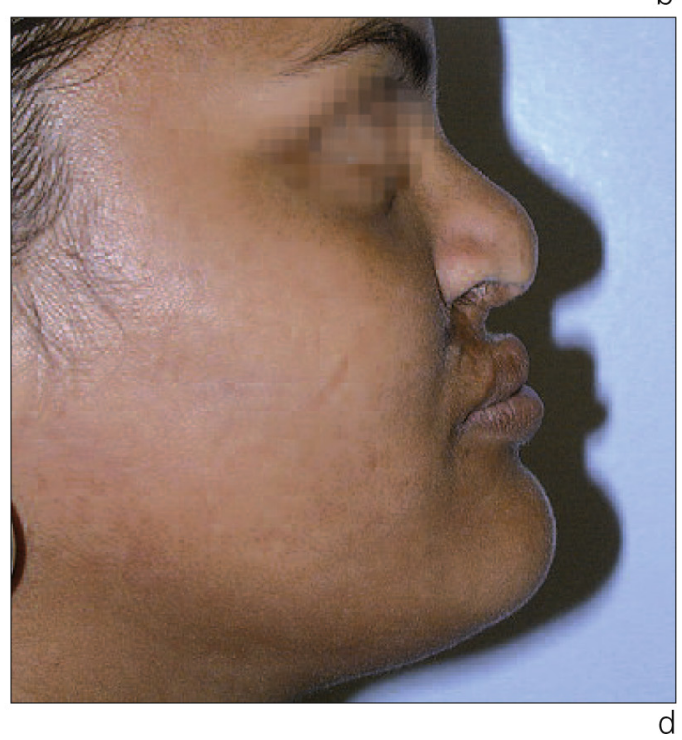

Figures 22a to $22 d$ Hetero-labial flap.

This patient's only concern is her upper lip, mutilated by previous procedures and constricting the base of the nose $(a, b)$. Note the effectiveness $(c, d)$ of the procedure and the discretion with which the surgeon harvested material from the lower lip, leaving virtually no scar as fullness was restored to upper lip with sufficient material remaining for future superficial retouching. correction. Starting out with a frank lipostructure, as used in face-lifts might be justified.

\section{5 - 3 - Isolated nasal sequelae}

Actually nasal sequelae can never be isolated. As the renowned plastic surgeon Ralph Millard has said, "Cleft lip surgery is nose surgery," and I have no wish to contradict the master. Let us mention here that a procedure for lengthening the nasal columella bears his name ${ }^{4}$. It employs a forked flap to restore the base of the nose in the lateral sectors of the prolabium while reshaping the philtrum at the same time (Fig. 23).

As for other defects, they require correction on corrected normal osseous bases with a wide range of 

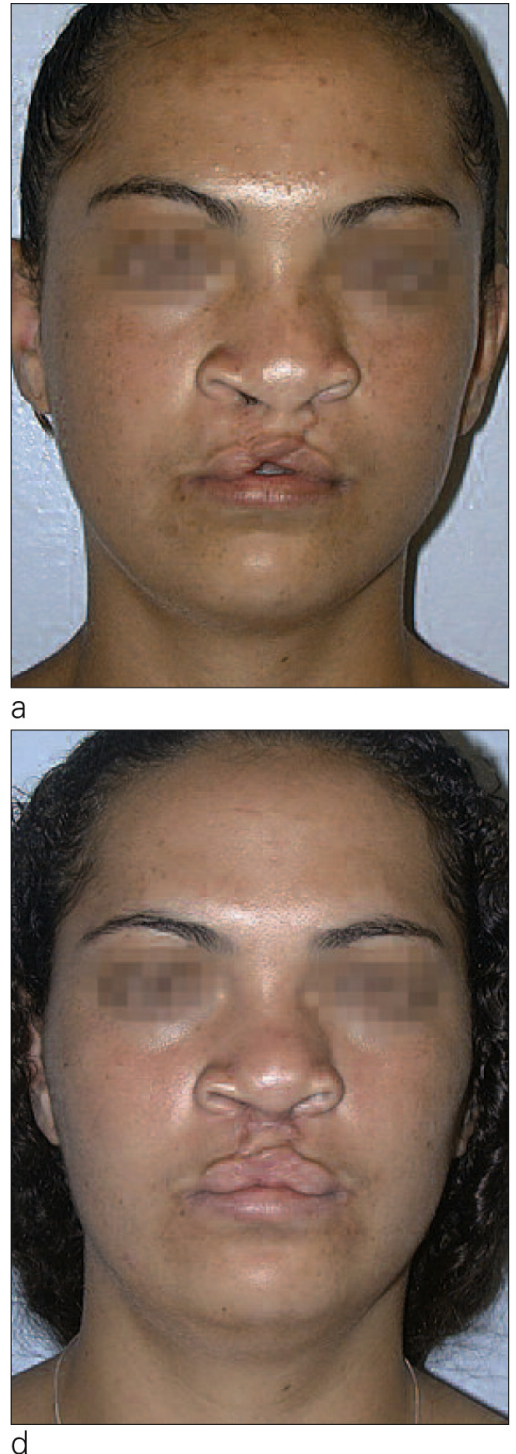

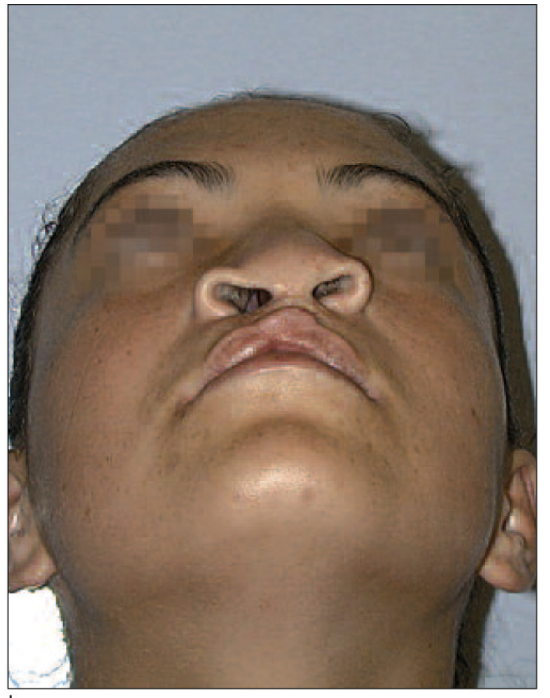

b

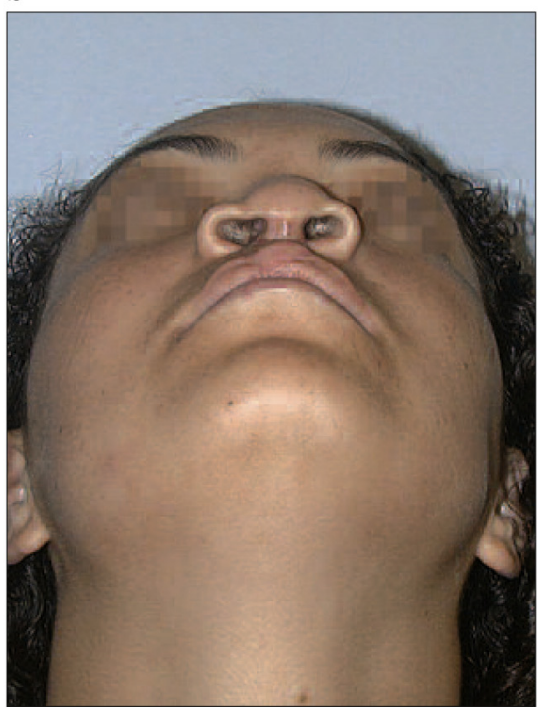

e
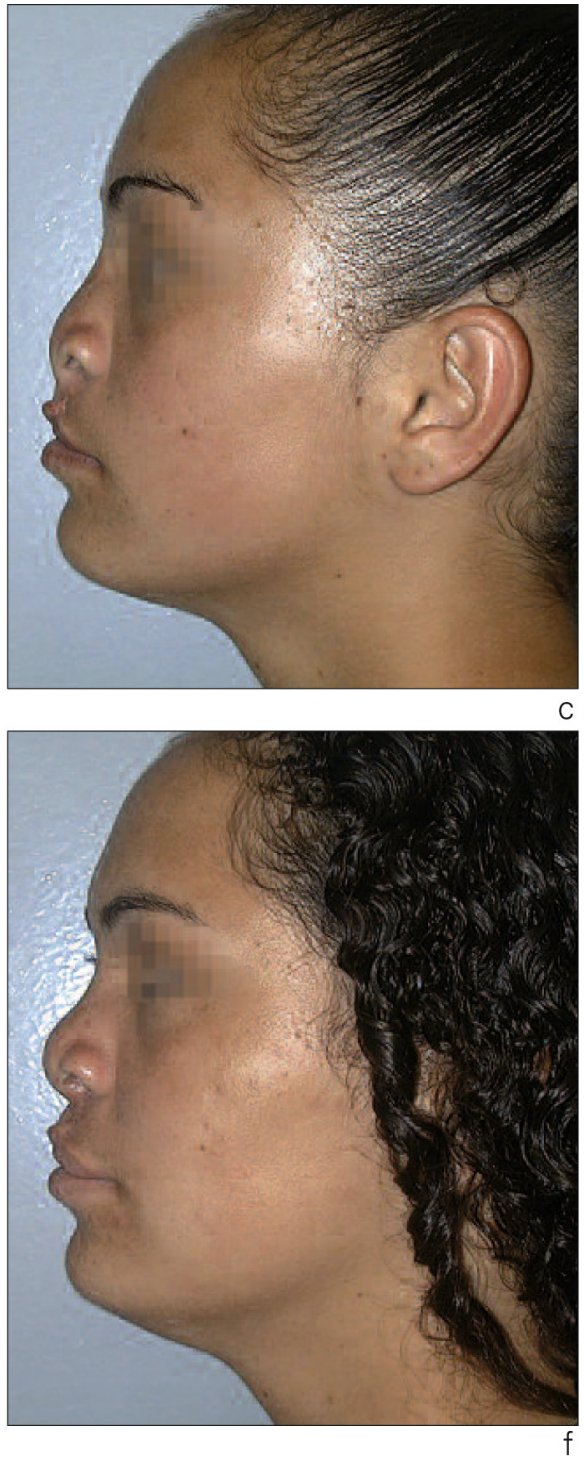

Figures 23a to $23 f$

Columella reconstruction with Millard's forked flap.

This "forgotten" procedure limited to the philtrum region was used in the initial intervention for this patient with a bilateral cleft to restore lip competence. The shape of the lip will later be retouched to show a cupid's bow whilst the columella is individualized to suit the patient. Pre- and post-operative facial views (a, d), sub-nasal views (b, e), and profile views $(c, f)$.

rhinoplasty techniques (Fig. 24) with the goal of not only repairing the anatomy of tegumentary and osteocartilaginous structures but also of preserving or restoring respiratory function, which may have been disturbed by a deviated nasal septum or a mal-positioned nasal valve. As A. R. Chancholles put it, "Form allows function, function perfects form ${ }^{2}$. 

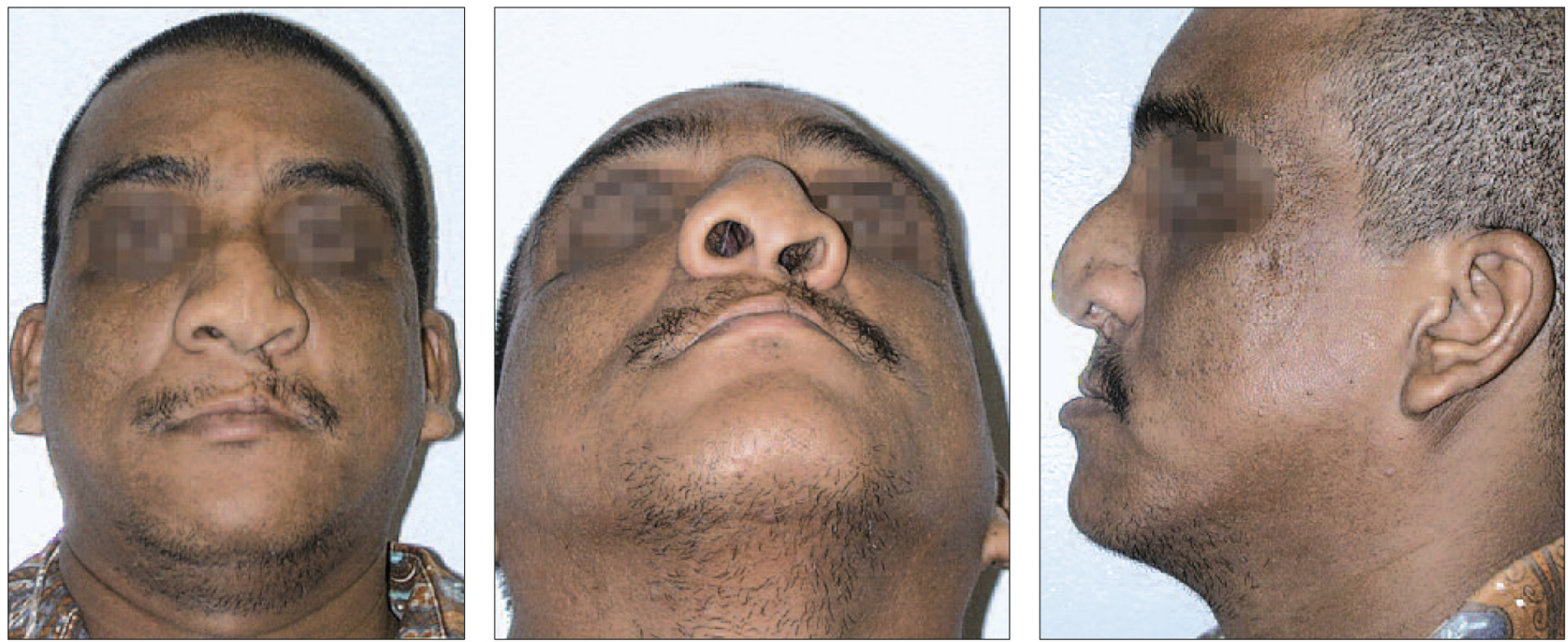

a

\section{b}

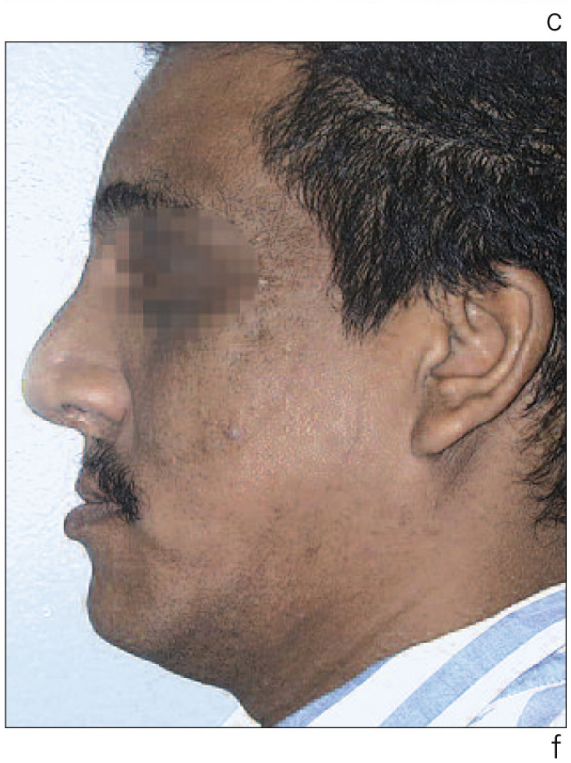

Figures 24a to $24 f$

Rhinoplasty following surgical repair of unilateral cleft.

External views of this patient show that surgery employing a cartilage graft could effectively improve the appearance of the point of the nose. Pre-operative facial views $(a, b, c$,$) and post-operative views (d, e, f)$. The result could be improved with pre-maxilla graft to raise the wing of the nose.

\section{$6-$ CONCLUSION}

Clearly a book could be written on the subject I have discussed in this article, describing its details and ar- guing the pros and cons of the techniques and sequences of treatment. Others before me have better 
expressed these topics than I ever could. Among these experts are my teachers A.R. Chancholles and J.-C. Talmant whose guidance was so precious to me at the beginning of my career. I wish to express to them my gratitude.

Because of the remote location in which I practiced, my experiences are far from typical but it remains true that wherever the treatment site may be located whoever may be the patient, even the best restored anatomic structures will have been bestowed on the patient too late. The time factor is critical for children for whom unhealthy adaptations and sequelae may develop. Children with clefts depend on their treatment teams to help them make their unavoidably difficult integration into their social milieu as free from stress as possible. They need us to resolve the functional and esthetic problems that burden them. Improvisation not being a routine surgical technique, cleft palate surgeons must be prepared to exploit the full panoply of techniques they learned in their training in order to obtain results that deserve the gratitude of patients. This specialty is difficult and not especially lucrative in terms of the time required to master it. But it is enormously gratifying and as John Lennon said, "It's a good job."

\section{REFERENCES}

1. Chancholle AR. Anatomie et physiologie pathologiques de la fente palatine: I'incompétence vélo-pharyngo-faciale. Ann Chir Plast 1980;25(3);205-11.

2. Magalon G, Chancholle AR. Chirurgie plastique de l'enfant. Pathologie congénitale. Paris: Maloine, 1987.

3. Mercier J. La gingivoplastie dans les fentes labiomaxillaires. Rev Stomatol Chir Maxillofac 2001; 102; 206-10.

4. Millard R. Principalization of plastic surgery. Boston/Toronto: Little, Brown and Co, 1986.

5. Orticochea M. Construction of a dynamic muscle shincter in cleft palates. Plastic Reconstr Surg 1968 Apr;41(4):323-7.

6. Picard A, Diner PA, Labbé D, Nicolas J,Tomat C, Seigneuric JB, Vasquez MP, Benateau $\mathrm{H}$. Les séquelles maxillaires dans les fentes labioalvéolopalatovélaires. Place de la distraction ostéogénique. Rev Stomatol Chir Maxillofac 2007;108(4):313-20.

7. Schweckendiek W. Primary veloplasty: long term results without maxillary deformity. A twenty five year report. Cleft Palate J 1978 Jul;15(3):268-74.

8. Stricker M, Chassagne JF, Meley M, Grunenwald J. Les lèvres, mutilations et réparations. Ann Chir Plast 1981;26(2):121-30.

9. Talmant JC. Nasal malformations associated with unilateral cleft lip. Scand J Plast Reconstr Surg Hand Surg 1993;27(3);183-91.

10. Talmant JC, Lumineau JP, Rousteau G. Prise en charge des fentes labio-maxillopalatines par l'équipe du docteur Talmant à Nantes. Ann Chir Plast Esthet 2002;47;11625. 